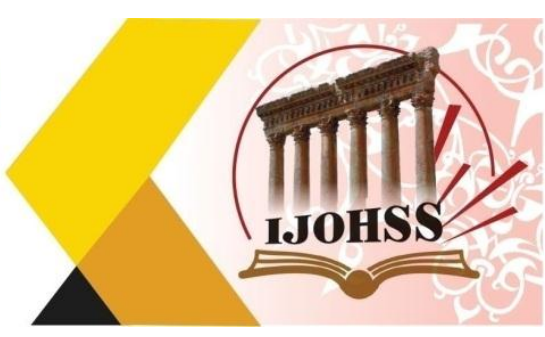

\title{
علم الإمام، حقيقته ومصادره
}

$$
\begin{aligned}
& \text { م.د. ستار عويد علي حميدة السراي } \\
& \text { قسم الفقه وأصوله } \\
& \text { كلية العلوم الاسلامية- جامعة وارث الانبياء } \\
& \text { كربلاء ـ العراق جاق وال }
\end{aligned}
$$

البريد الاكتروني: Sattarawed@gmail.com

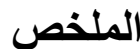

تعد الامامة من المسائل المهمة عند الثيعة الامامية بل هي واجبة عند جميع ابناء المذاهب الاسلامية وان اختلفوا

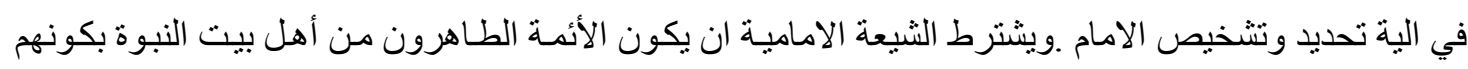
أعلم الناس بمعارف الثريعة الإسلامية وتعاليمها وأحكامها وبالقرآن الكريم و علومه وتفسير آياته وبيانهـ وتوضيح

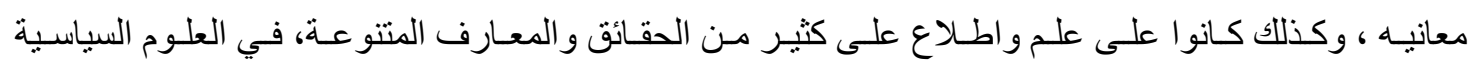
الاقتصادية و الصحية و التاريخية و الاجتماعية وغيرهـا ، ويتعدى ذلك العلم لدرجة إنهم أخبروا بأمور لا سبيل

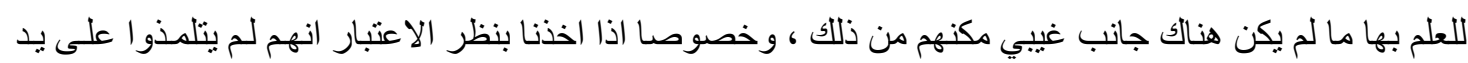

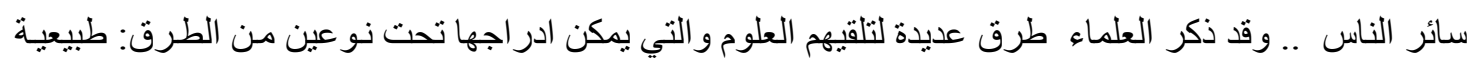
و غيبية ولكي تتضح أكثر لابد لنا من تسليط الضوء عليها. الكلمات المفتاحية: علم الإمام، الإمامة، الغيب. 


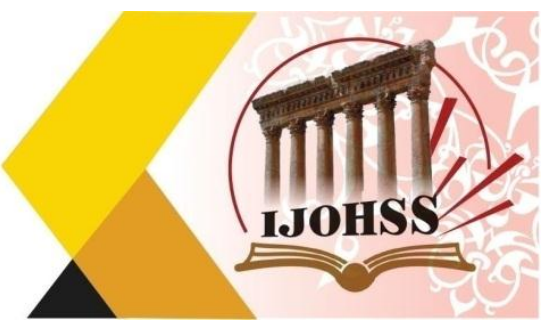

\title{
The Knowledge of the Imam, his Truth and Sources
}

\author{
Dr. Sttar Owaid Ali Hamida Al-Saray \\ Department of Jurisprudence and its Fundamentals \\ College of Islamic Sciences - University of Warith Al-Anbiya \\ Karbala - Iraq \\ Email: sattarawed@gmail.com
}

\begin{abstract}
The Imamate is one of the important issues for the Imami Shiites. Rather, it is obligatory for all the sons of Islamic sects, even if they differ in the mechanism of identifying and diagnosing the Imam. The Imami Shiites require that the pure imams be from the people of the Prophet's House by being the most knowledgeable of the people about the knowledge of Islamic Sharia, its teachings and rulings, the Holy Qur'an and its sciences, the interpretation of its verses, its statement and clarification. Their meanings, as well as they were aware and familiar with many facts and various knowledge, in political, economic, health, historical, social and other sciences, and beyond that knowledge to the extent that they were told of things that were not known to them unless there was a metaphysical aspect that enabled them to do so, especially if we take into account They were not taught by other people.. The scholars mentioned many ways for them to receive knowledge, which can be included under two types of methods: natural and metaphysical. In order to become more clear, we must shed light on them.
\end{abstract}

Keywords: The knowledge of the Imam, the Imamate, the Unseen. 


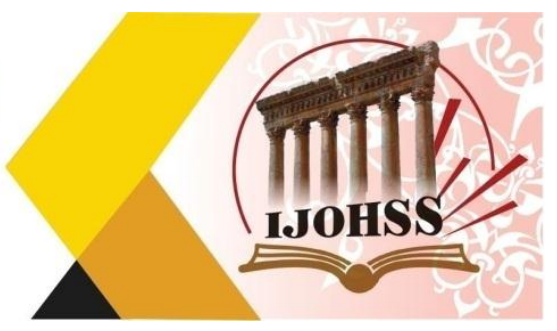

المقدمة

الحمد لله رب العالمين و الصـلاة و السـلام على اشـرف الانبياء و المرسلين ابي القاسم محمد و على الـه الطـاهرين

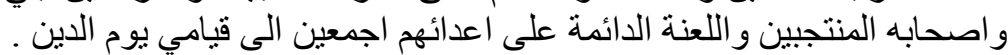

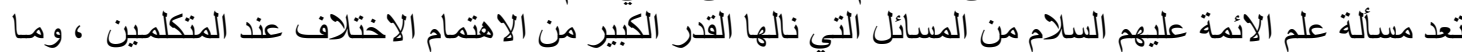

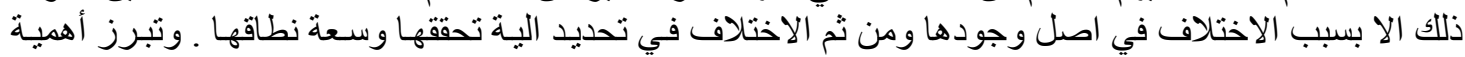

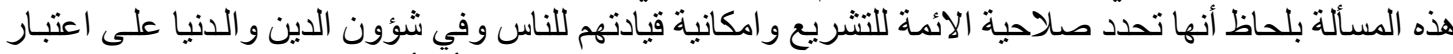

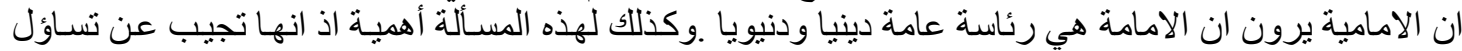

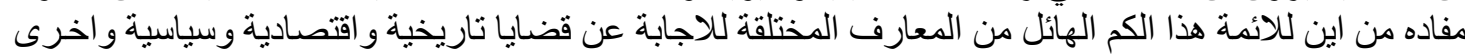

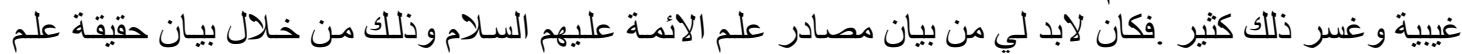

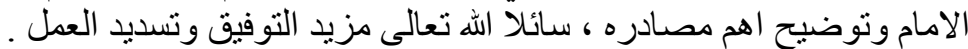

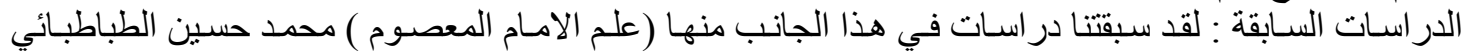

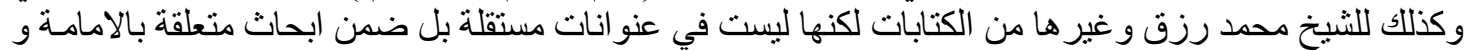

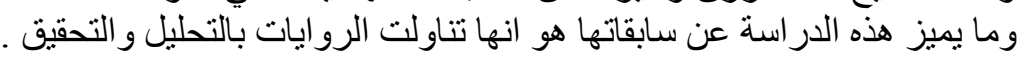

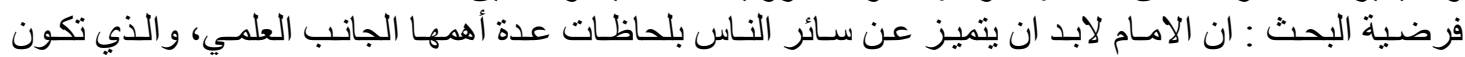

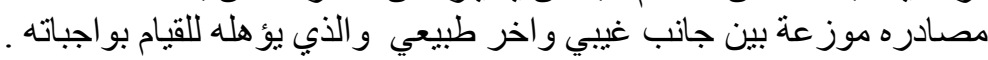

المبحث الأول: بيان علم الإمام والادلة عليه

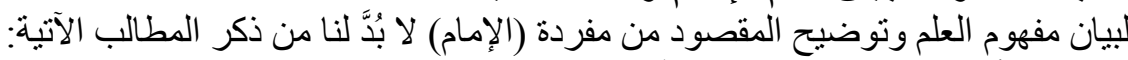
المطلب الأول: العلم والإمام في اللغة والاصطلاح

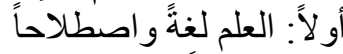

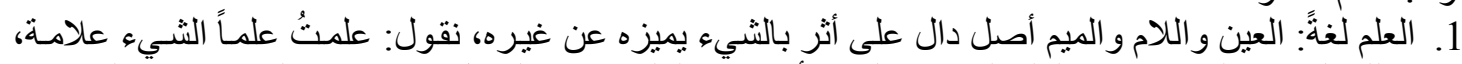

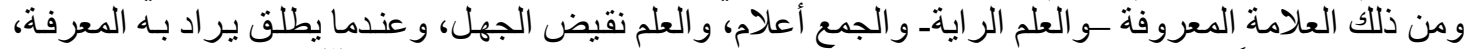

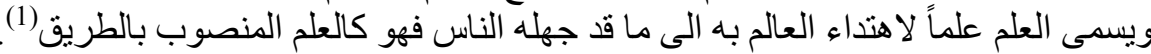

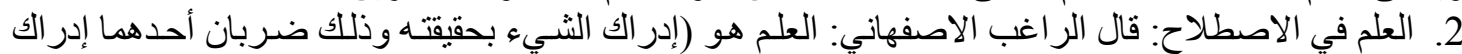

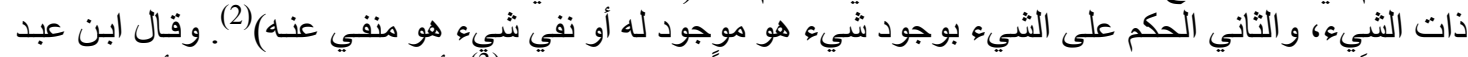

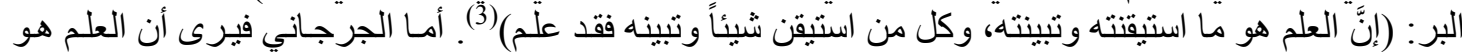

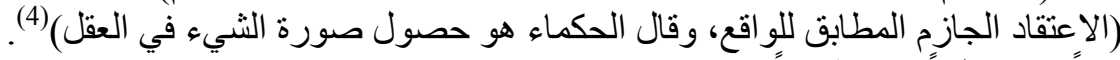

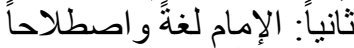

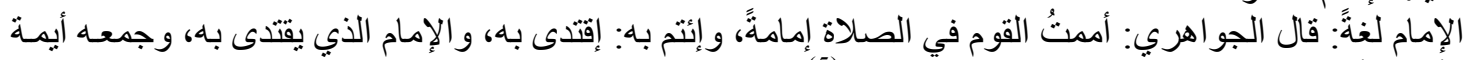

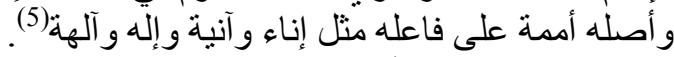
و الإمامة هي: (التقام أمام القوم وتقدمهم، والإمام من إنتم به الناس من رئيس و غيره، هادياً كان أو ضالاً، ويطلق

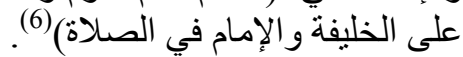
أما الإمام إصطلاحاً

فهو من له (الرئاسة العامة في أمور الدنبا والدين) (7).

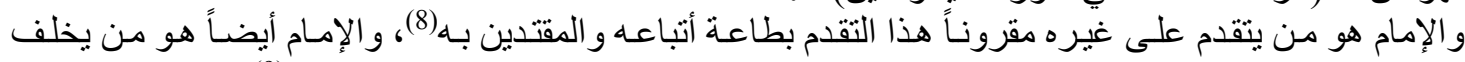

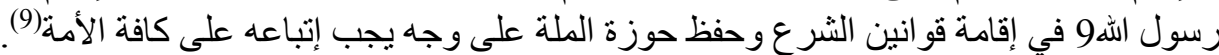

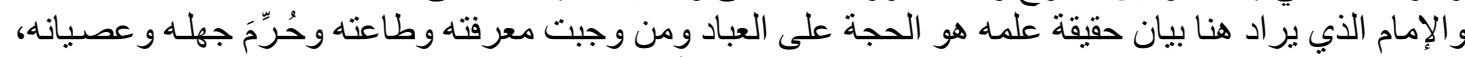

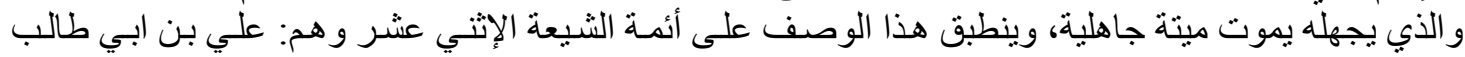

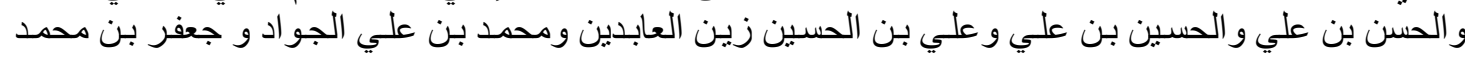

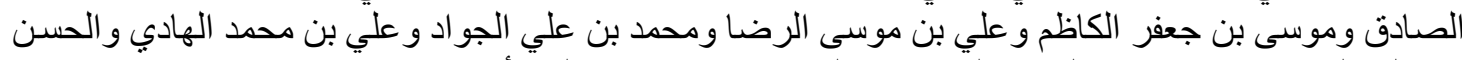
بن علي العسكري ومحمد بن الحسن الدهدي (صلو ات ربي وسلامبا وسل عليهم أجمعين). 
International Journal on Humanities and Social Sciences

website:www.ijohss.com

Email:editor@ijohss.com

العدد (29) يناير 2022

ISSN: $2415-4822$

Volume (29) January 2022

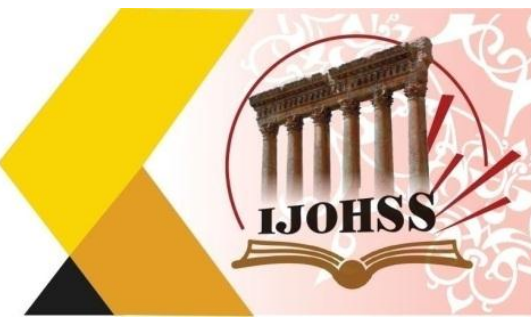

المطلب الثاني: آراء العلماء في علم الإمام

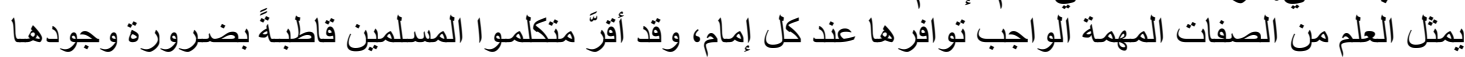

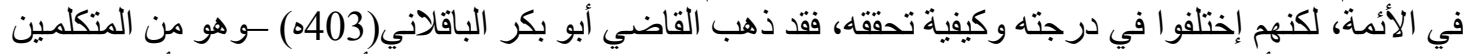

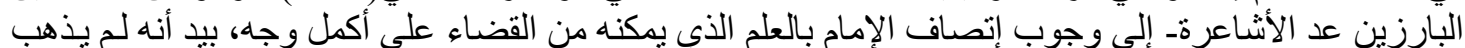
المى ضرورة إنصافه بعلم الغيب(10). أما المعتزلة فقد ذهب أبرز متكلميهم القاضي عبد الجبار الهمداني(10 415ه) الى أن العلم الاجتهادي الذي الذي يتيح للإمام

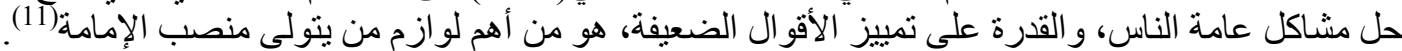

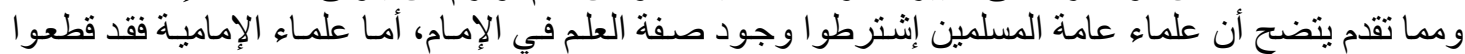

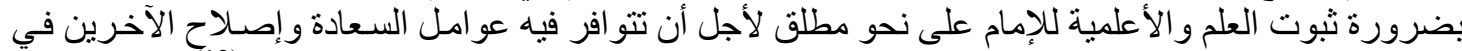

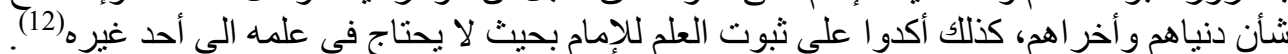

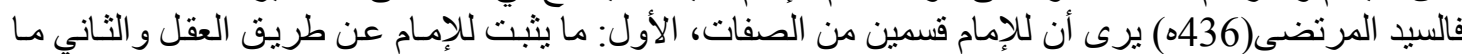

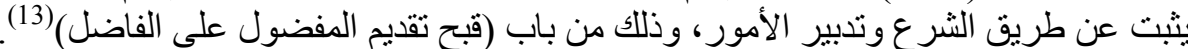

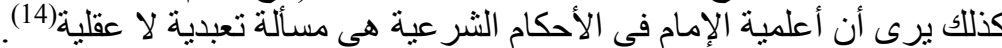

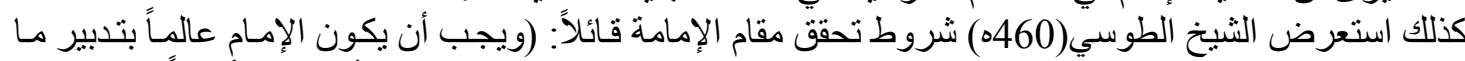

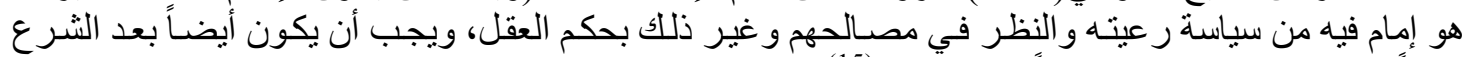

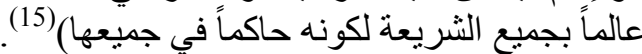

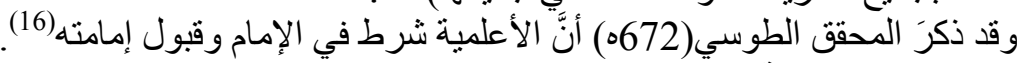

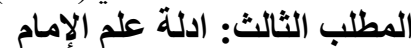

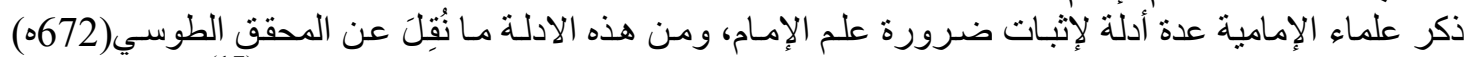

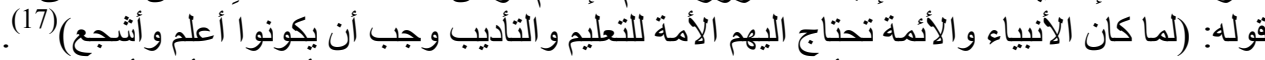

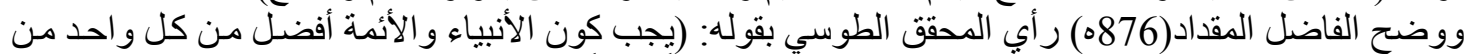

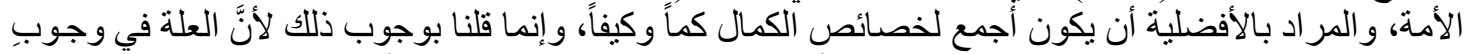

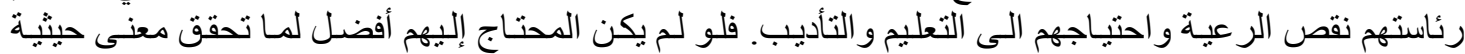

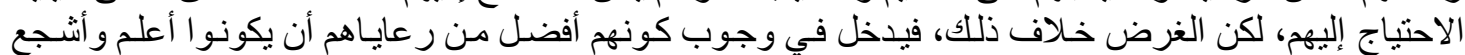

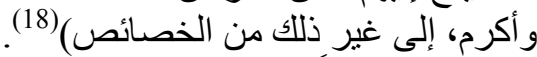

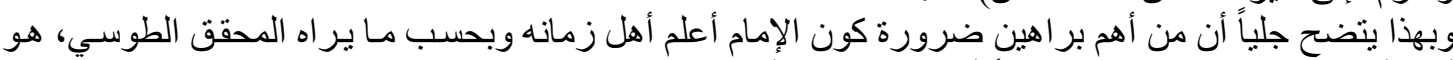

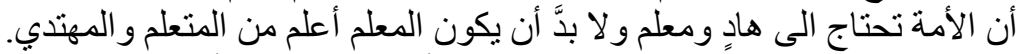

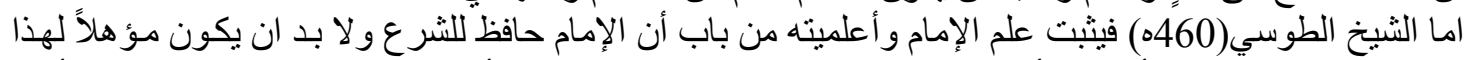

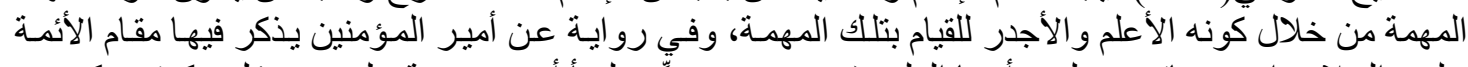

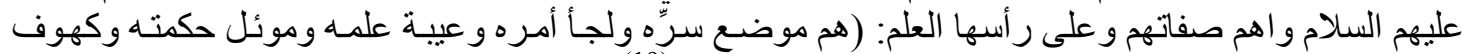

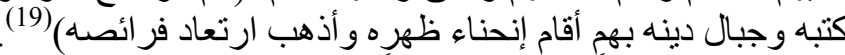

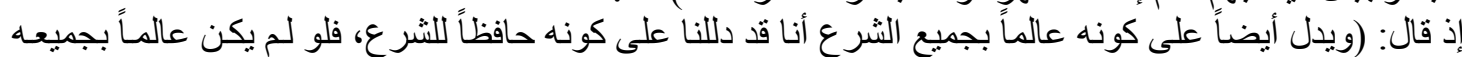

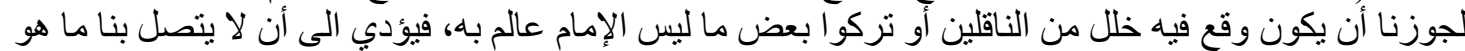

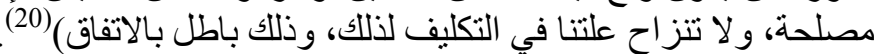

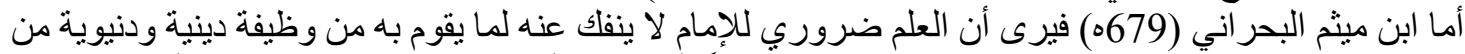

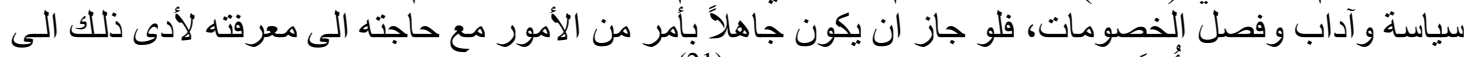

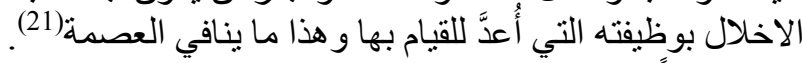

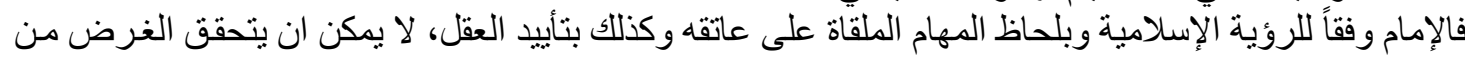

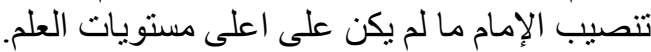

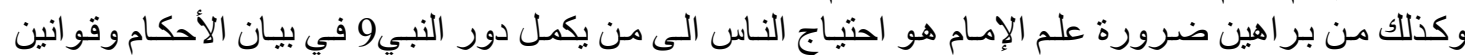

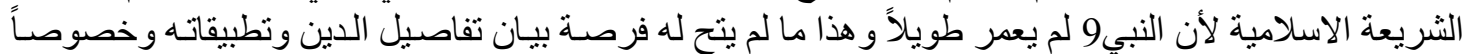

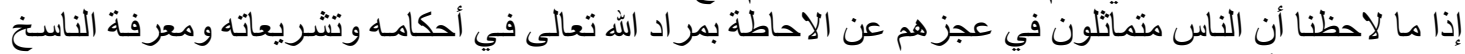

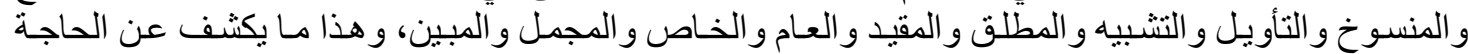




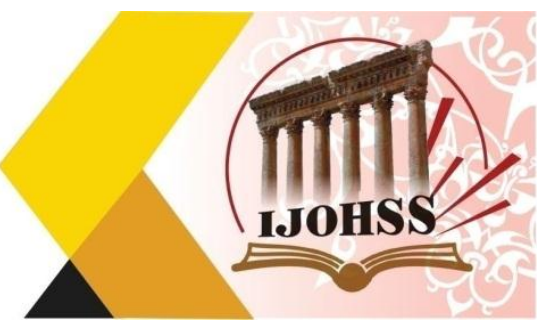

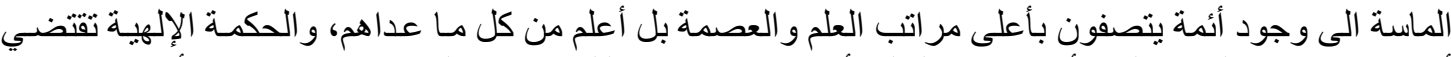

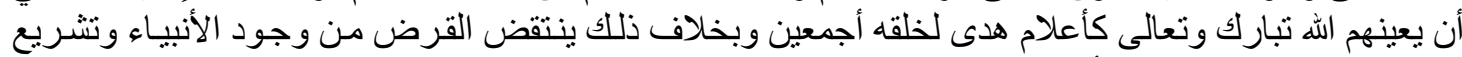

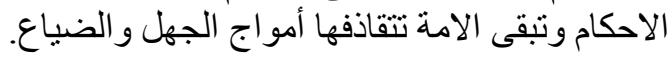

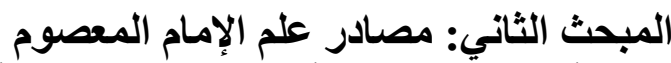

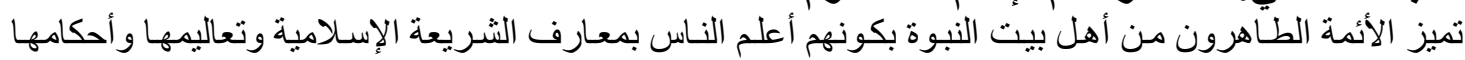

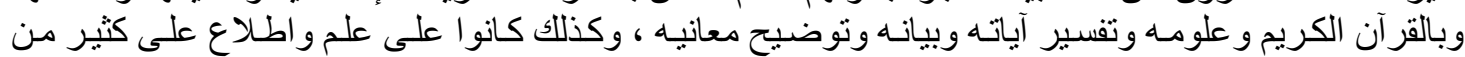

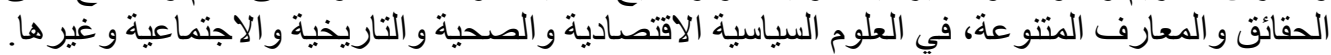

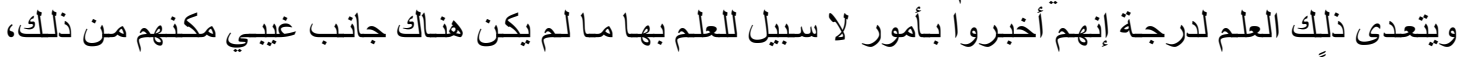

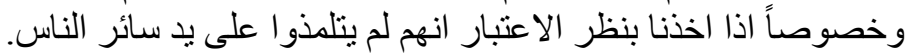

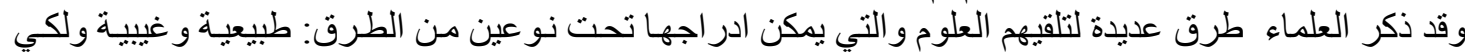

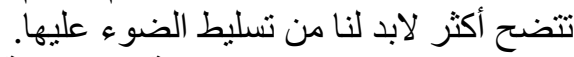
المطلب الاول: المصادر الطبيعية لعلم الائمة

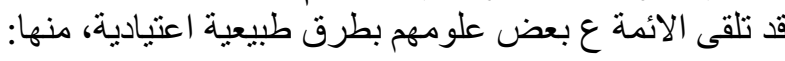

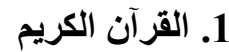

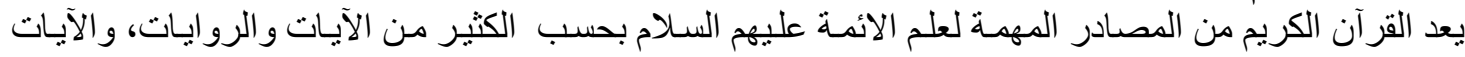

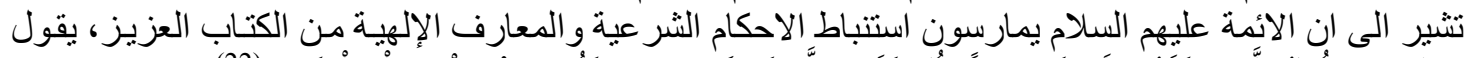

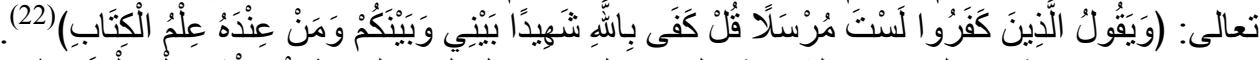

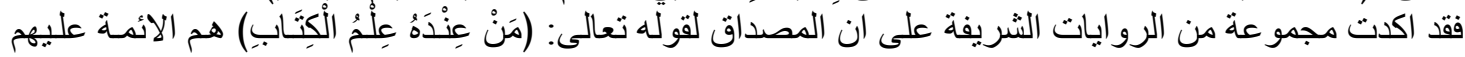
السلام. وقد أجاب الامام محمد الباقر عليه السلام عن تلك الآيـة فقال: (انها نزلت في علي بن ابي طالب أنه عالم هذه

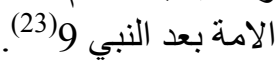

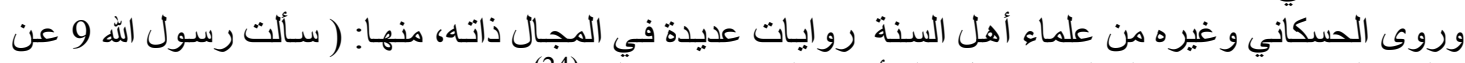

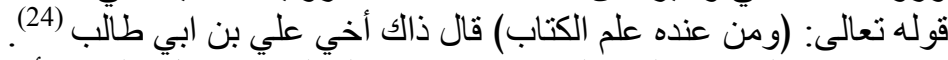

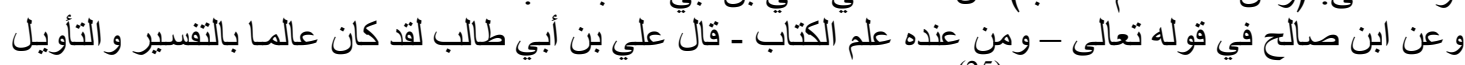

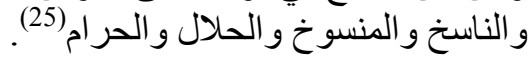

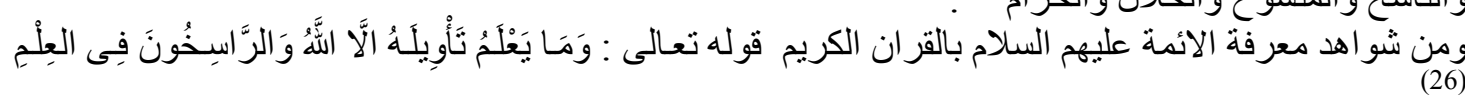

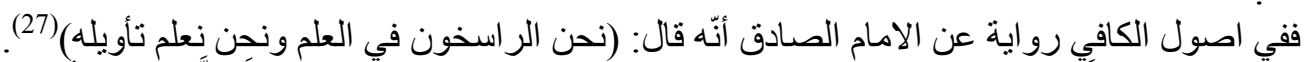

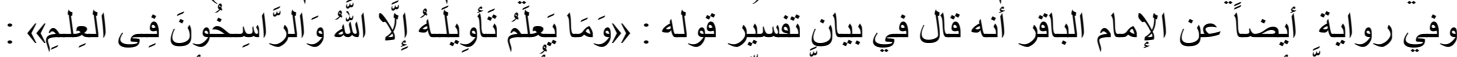

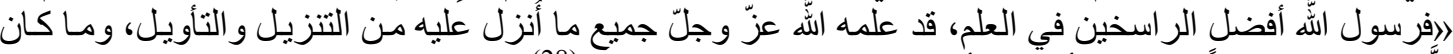

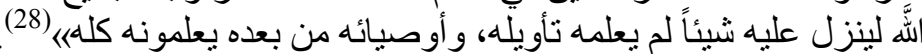

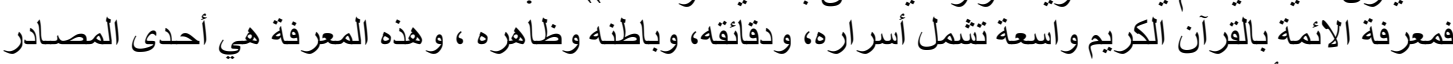

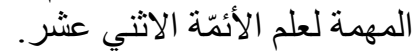

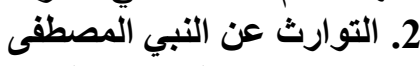

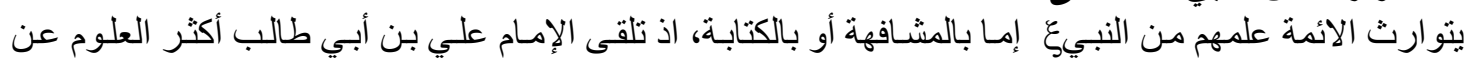

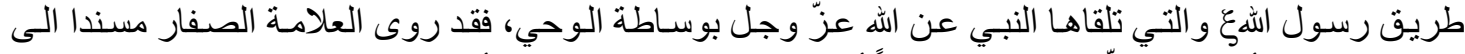

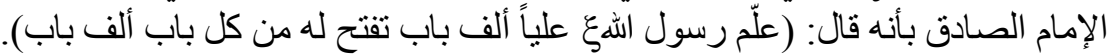

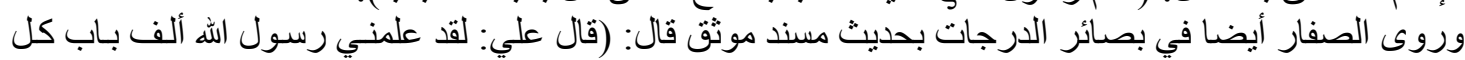

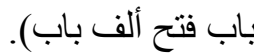

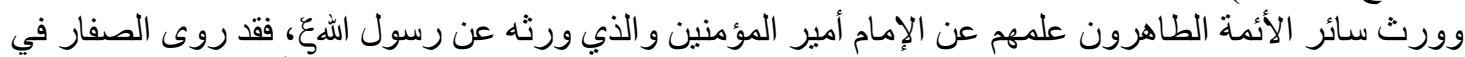

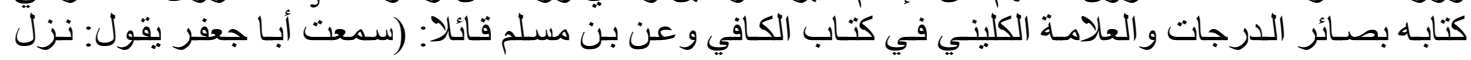




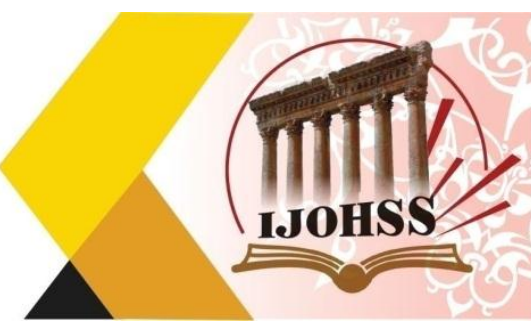

جبر ائيل على محمد9 برمانتين من الجنة فلقيه علي فقال له: ما هاتان الرمانتان؟ قال: أما هذه فالنبوة ليس للك فيها

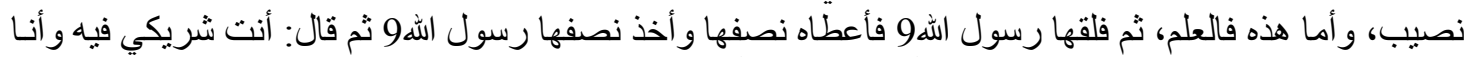

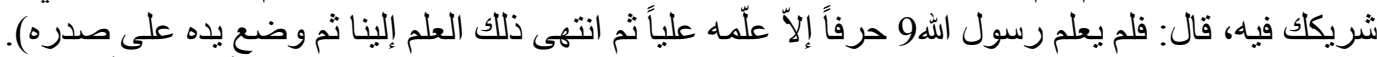

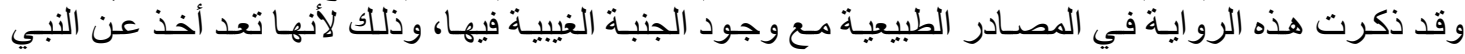

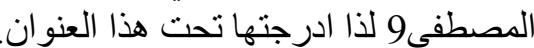

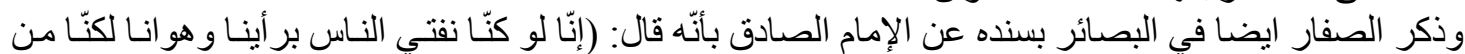

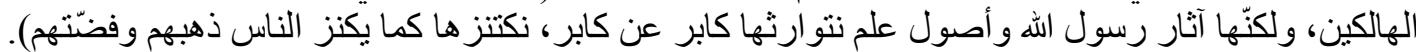

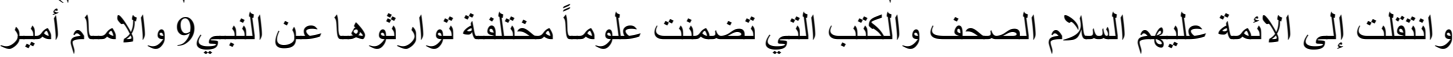
المؤمنين.

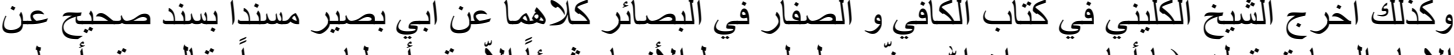

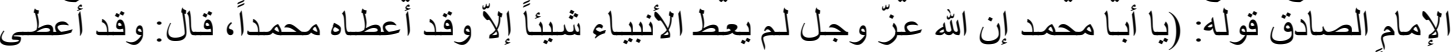

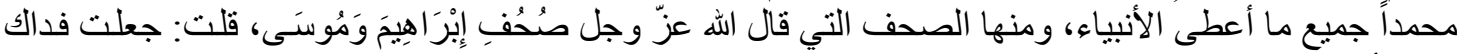

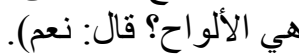
ومن الجدير بالذكران هناك روايات عديدة تثنير الى ان حديث كل واحد منهم هو حديث رسول الله لانهم سمعوا

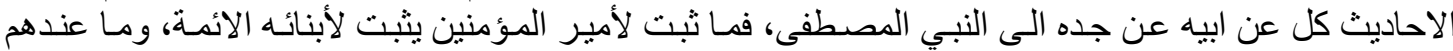

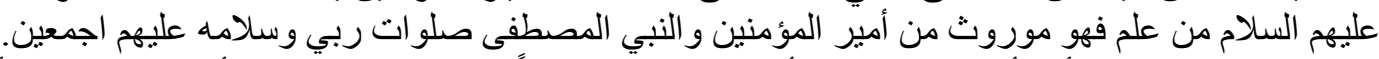

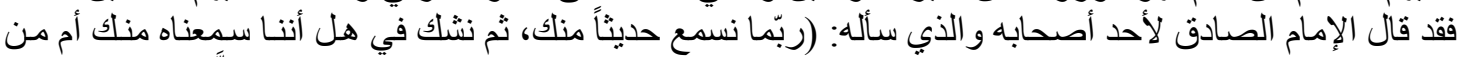

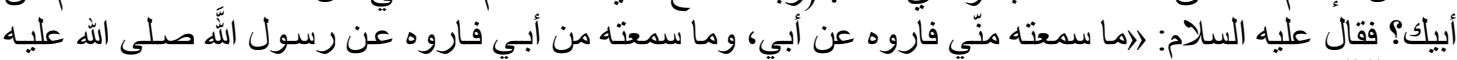
(29)

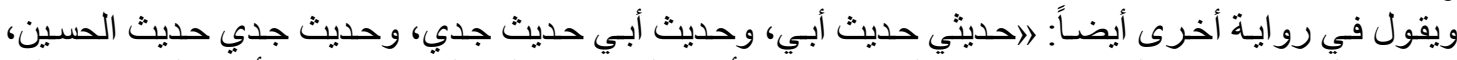

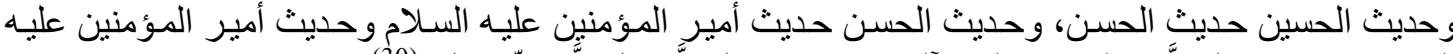

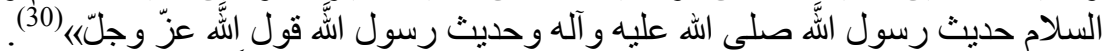

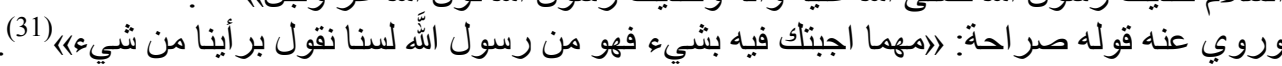

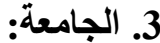

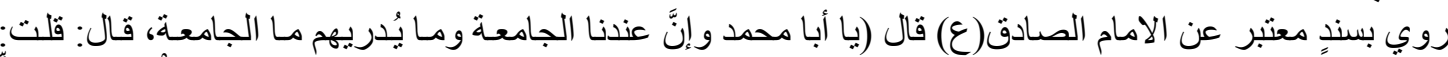

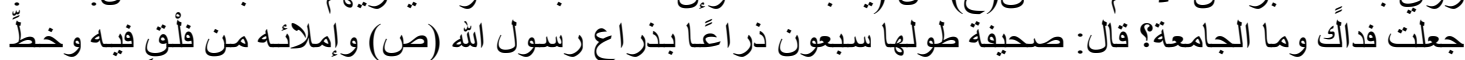

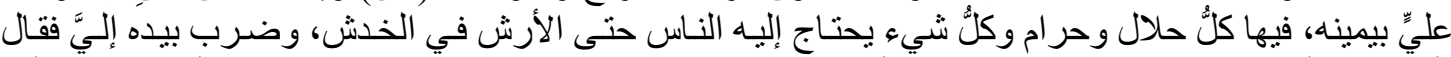

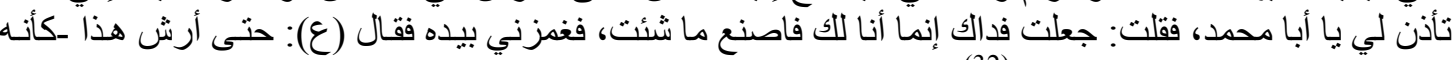

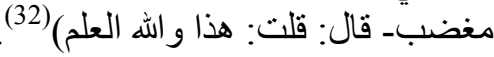

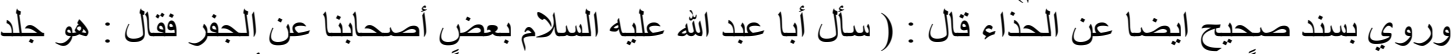

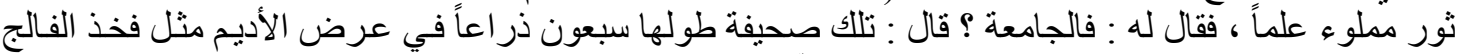

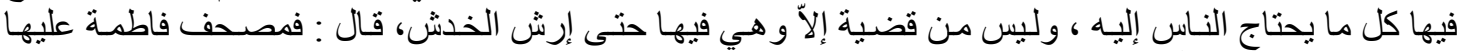

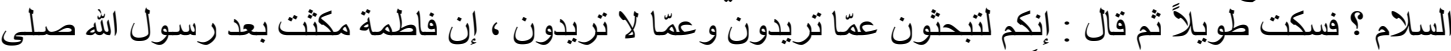

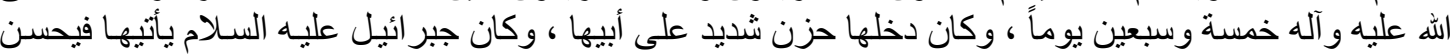

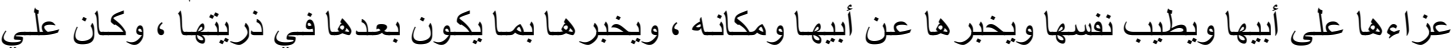

يكتب ذلك، فهذا مصحف فاطمة ) (33).

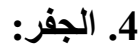

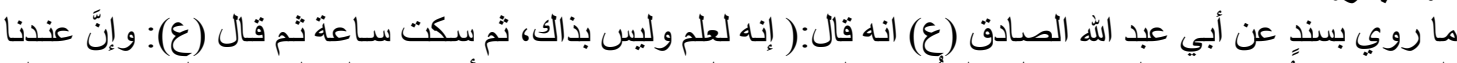

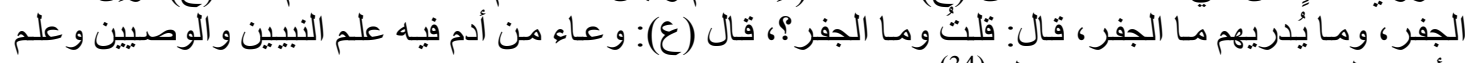

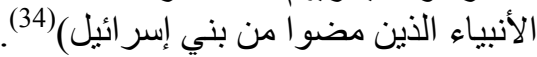

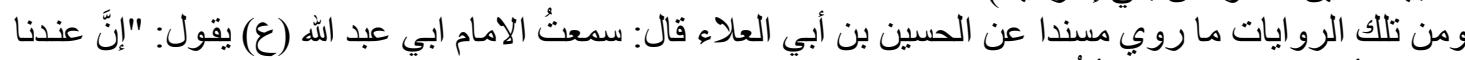

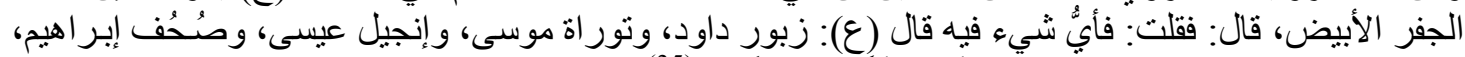

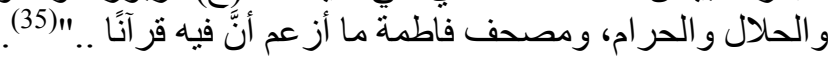


International Journal on Humanities and Social Sciences

website:www.ijohss.com

Email:editor@ijohss.com

ISSN: $2415-4822$

العدد (29) إناير 2022

Volume (29) January 2022

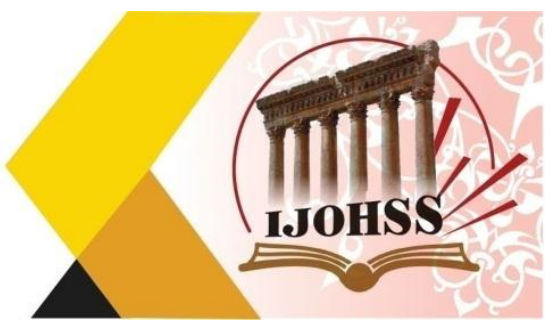

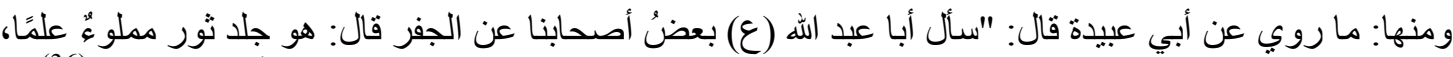

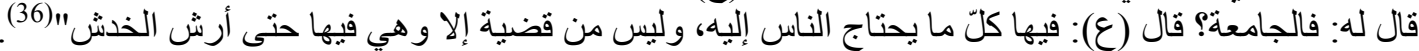

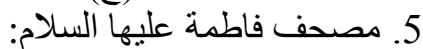

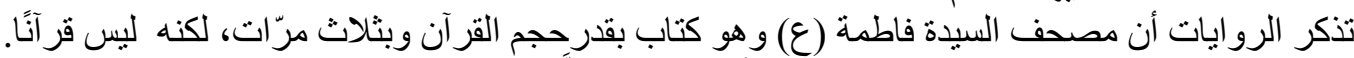

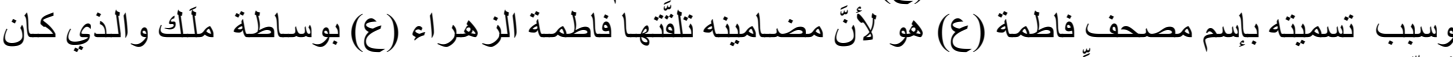

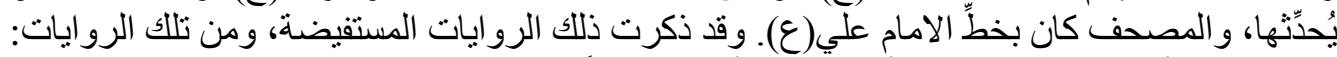

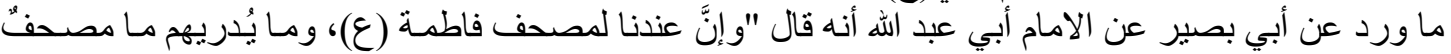

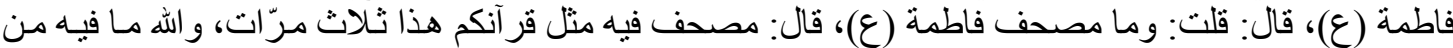

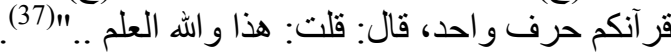

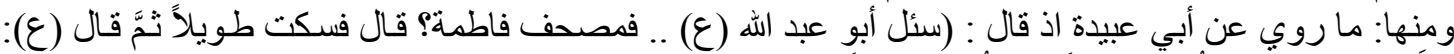

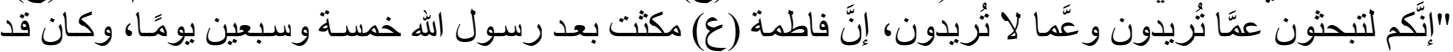

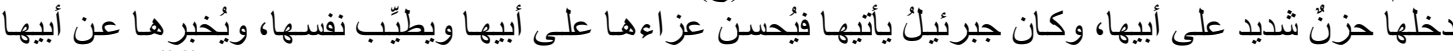

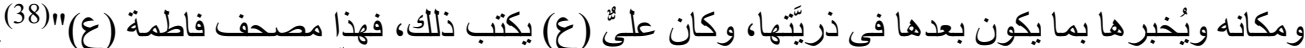

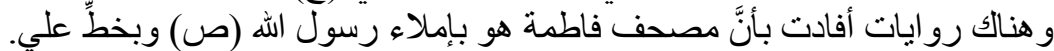

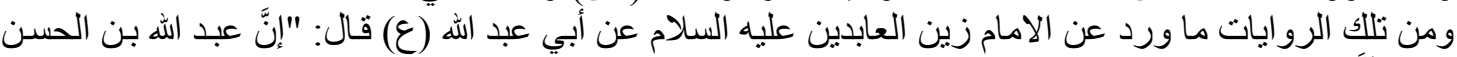

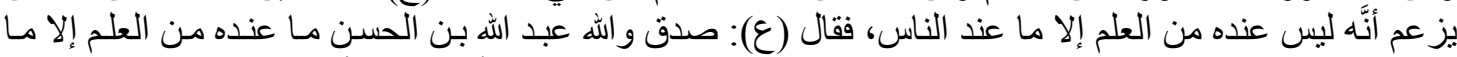

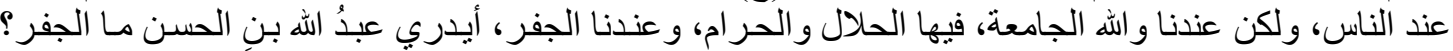

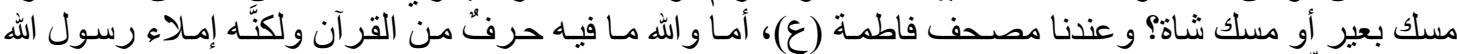

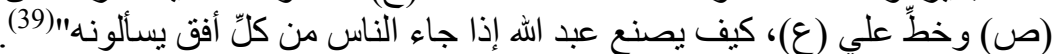

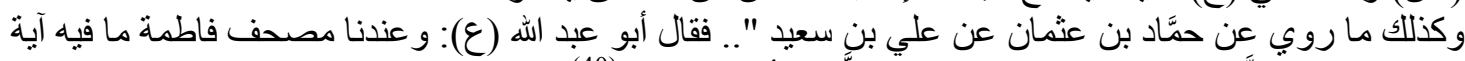

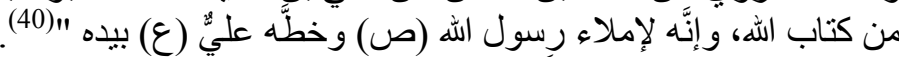

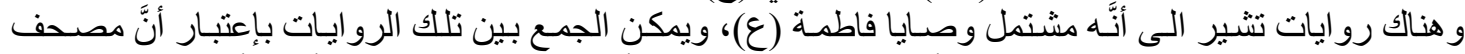

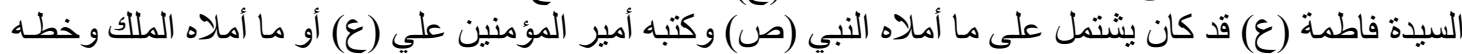

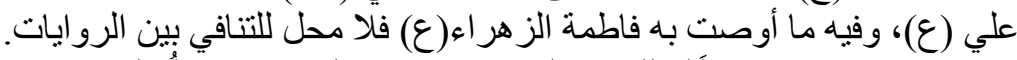

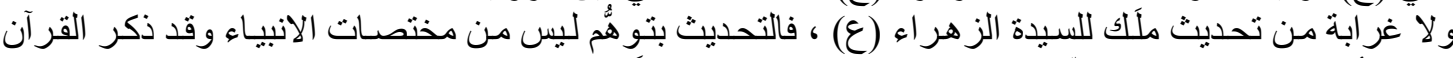

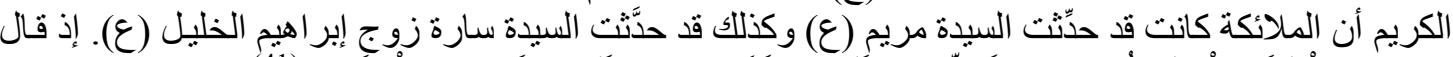

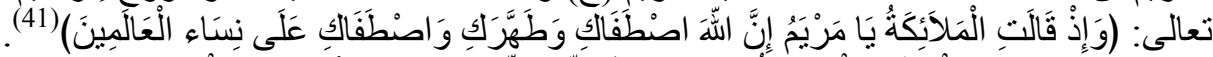

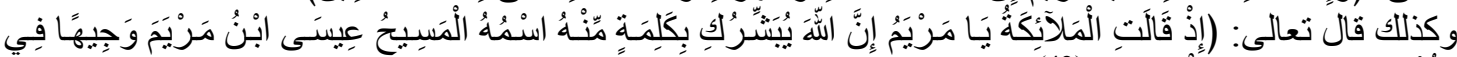

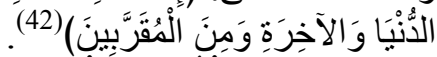

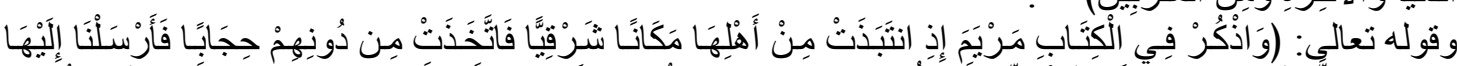

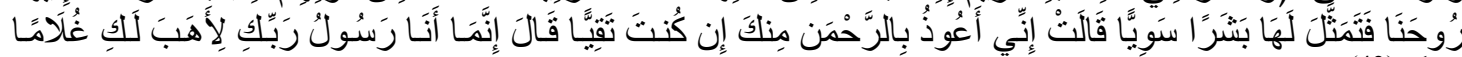

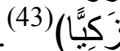

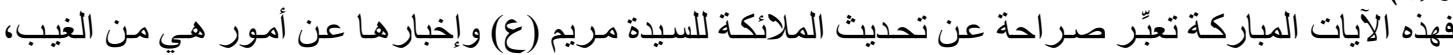

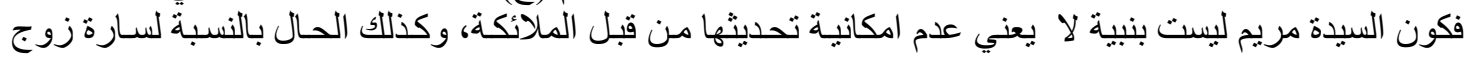

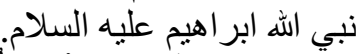

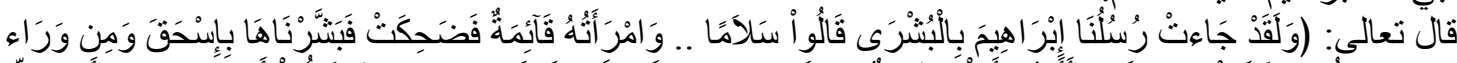

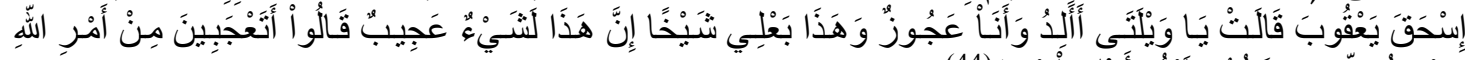

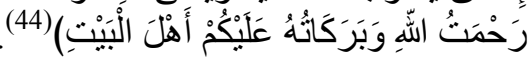

المطلب الثًاني: المصادر الغيبية لعلم الائمة

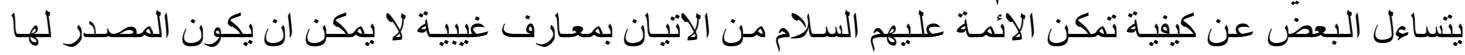

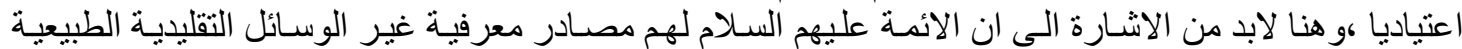

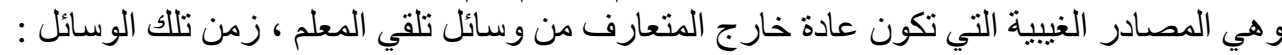

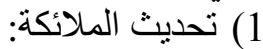


International Journal on Humanities and Social Sciences

website:www.ijohss.com

Email:editor@ijohss.com

العدد (29) يناير 2022

ISSN: $2415-4822$

Volume (29) January 2022

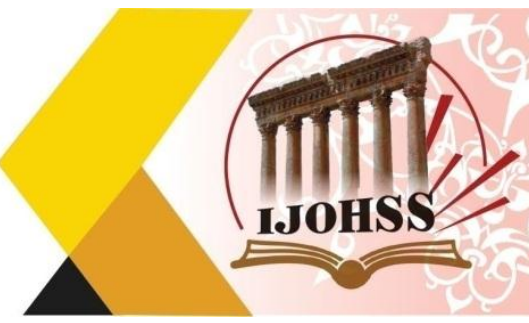

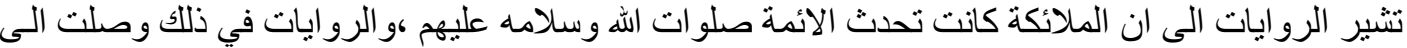

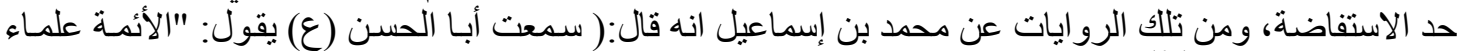

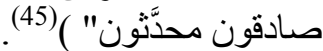

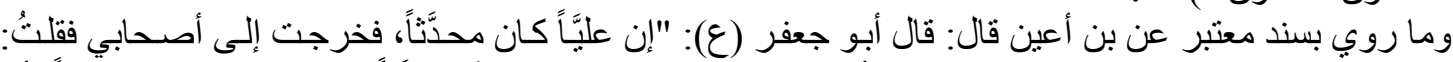

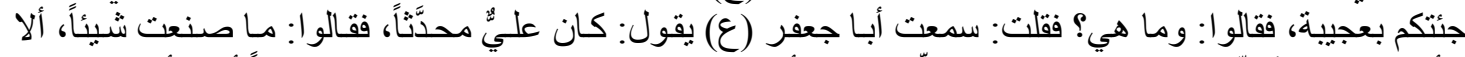

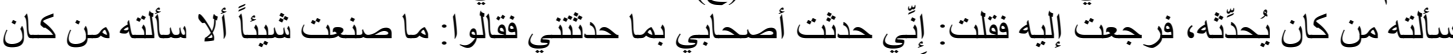

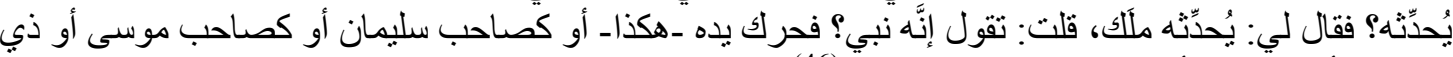

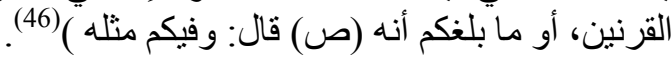

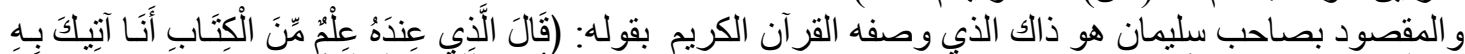

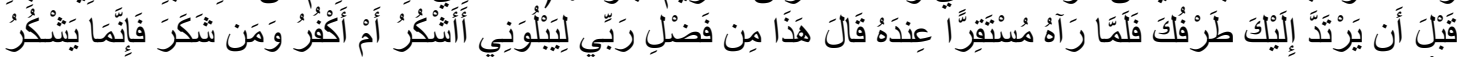

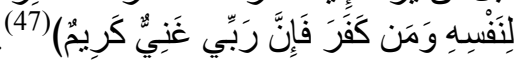

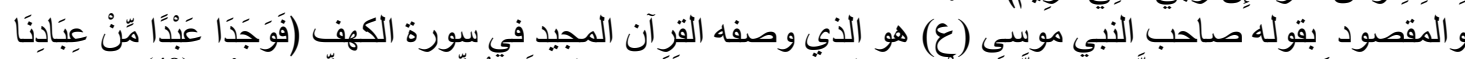

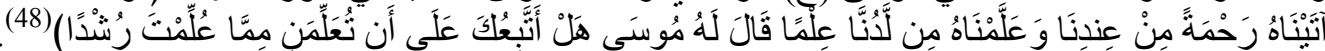

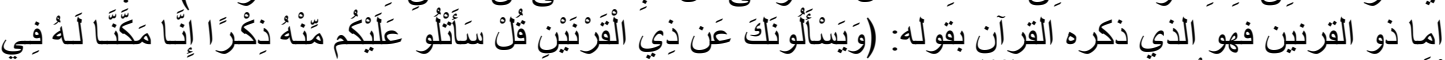

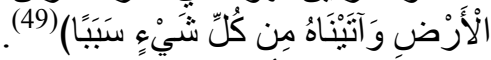

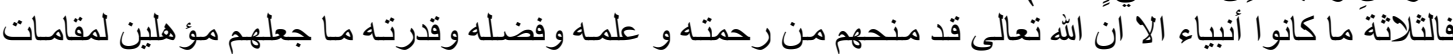

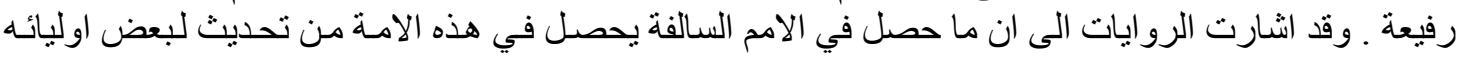

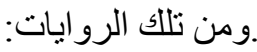

روي بسند عن عبيد بن زرارة قالن: (أرسل أبو جعفر إلى زرارة أن يعلم الحكم بن عنيبـة أن أوصياء محمد عليه

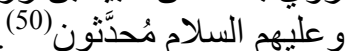

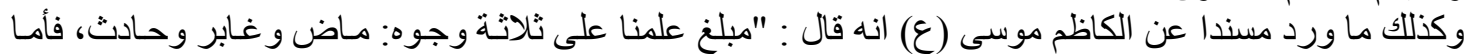

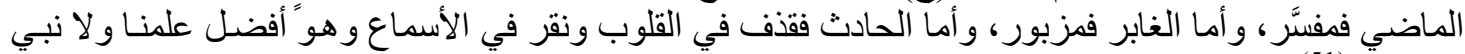

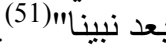

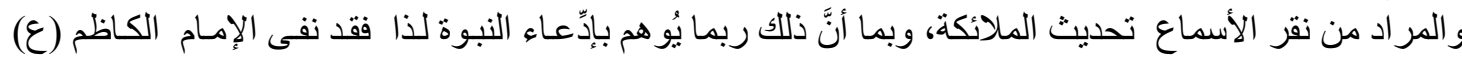

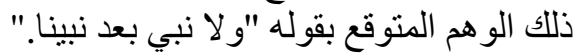

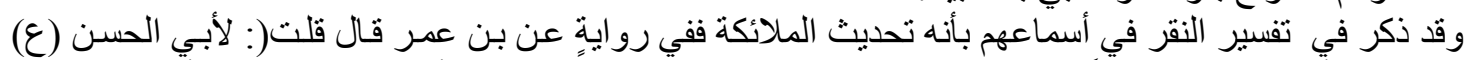

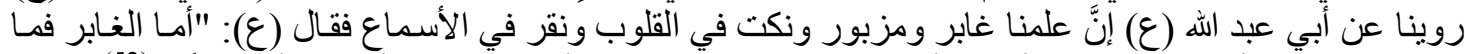

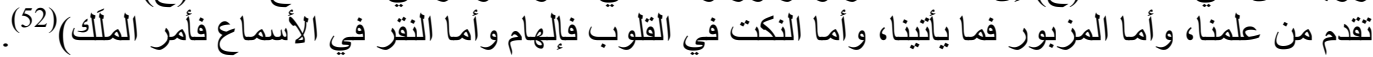

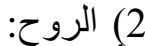

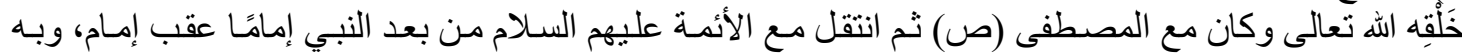

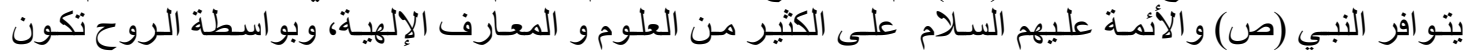
العصمة و التسديد. وليس بمقدور الانسان أن يدرك حقيقة هذه الروح، فإن ذللك أمر مستصعب، فلا يتعدى فيهـ مقدار مـا أفادت بـهـ الروايات الكثيرة و التي فاقت حدَّ الاستفاضة:

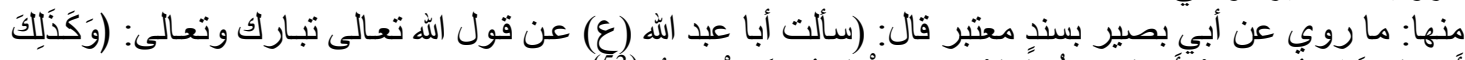

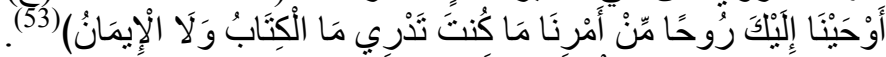

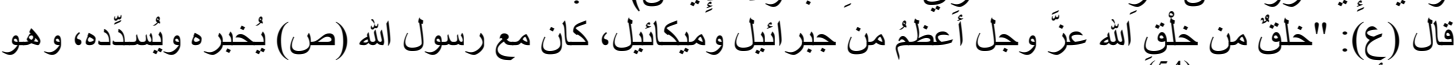

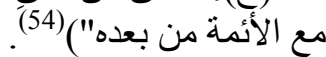

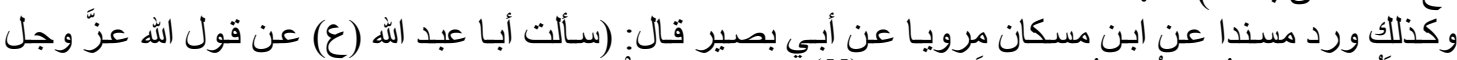

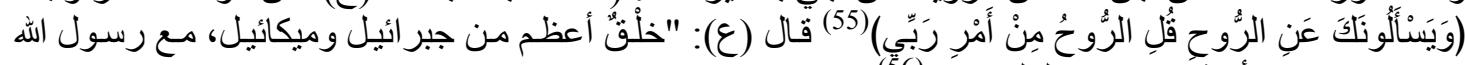

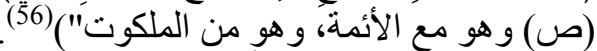

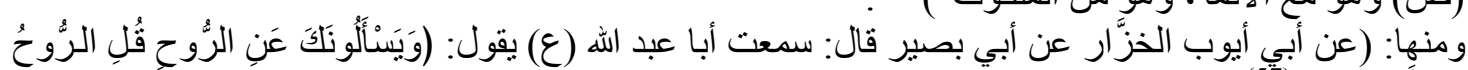
مِنْ أَمْرِ رَبِّيَ)( 


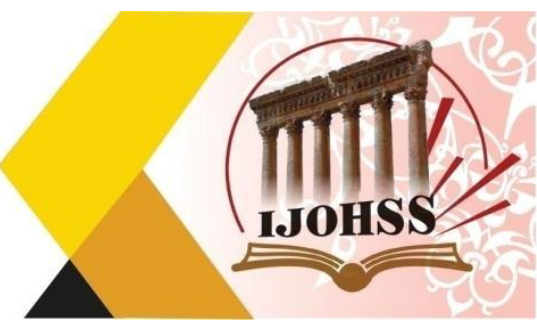

قال (ع): "خلْقٌُ أعظم من جبرئيل وميكائيل لم يكن مع أحدٍ ممن مضى غير محمد (ص) وهو مع الأئمة يُسدِّدهم،

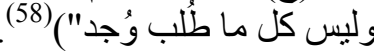

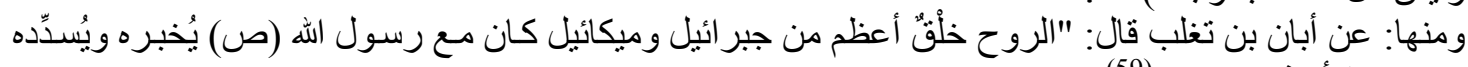

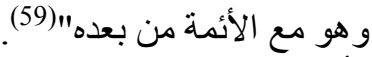

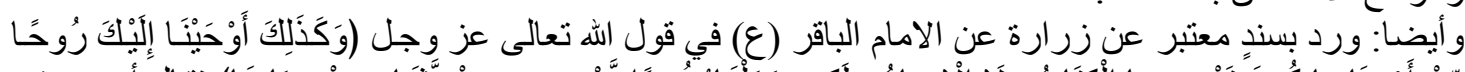

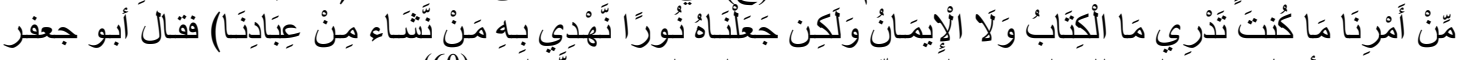

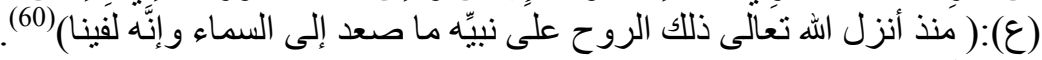

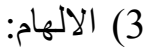
و هو إلقاء الحقائق و المعارف و المعاني في القلب بوسـاطة فيض إلهي أب دون اكتساب، و الروايات تعبر عنـهـ بالقذف أو النكت في القلب.

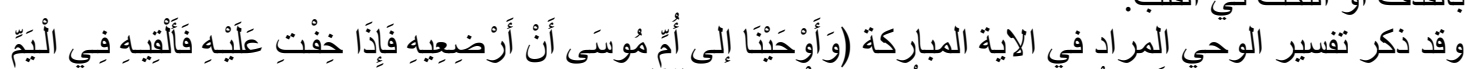

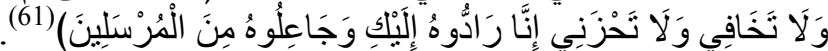

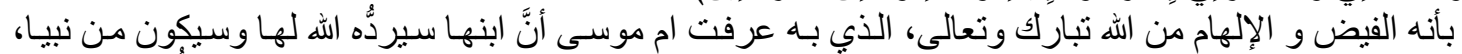

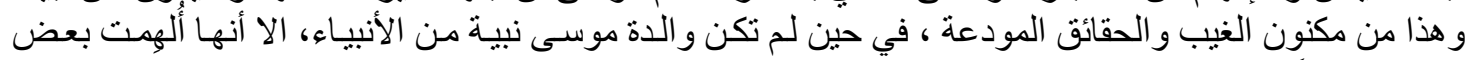
الحقائق الغيبيَّة.

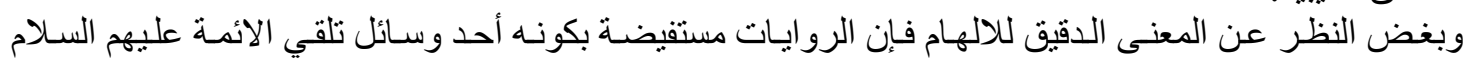

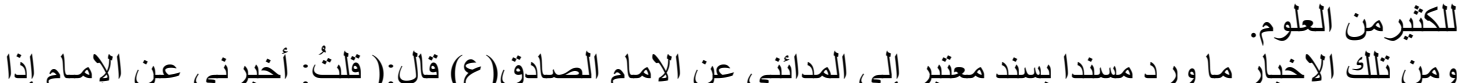

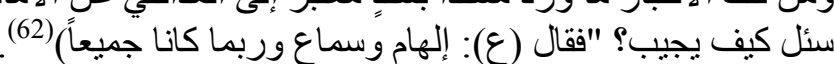

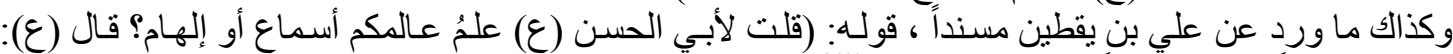

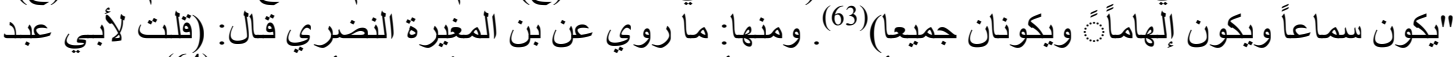

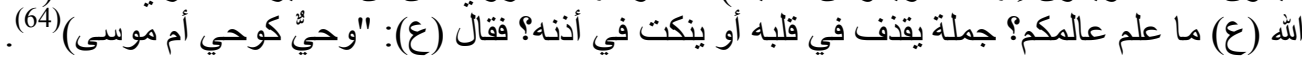

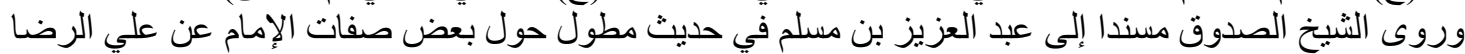

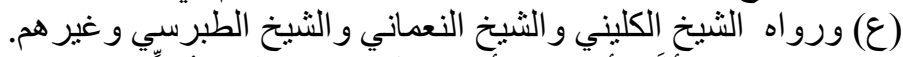

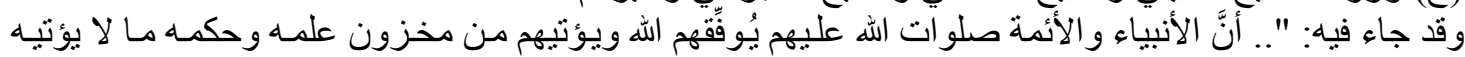

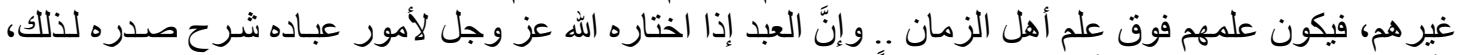

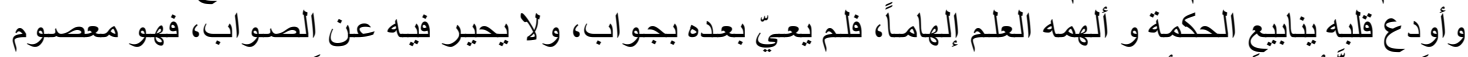

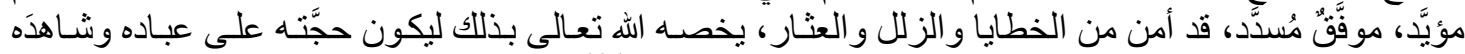

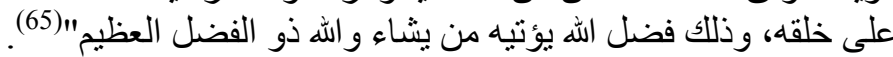

\section{المبحث الثالث: اشكالات علم الائمة}

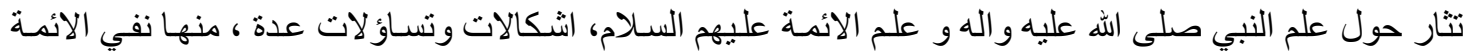

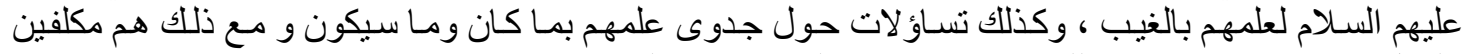

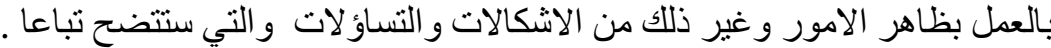

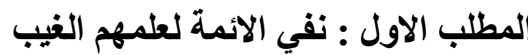

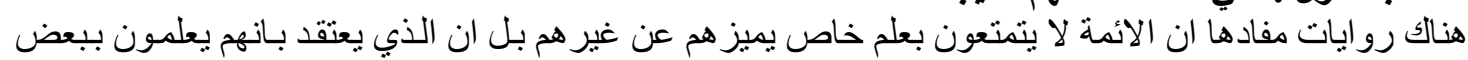

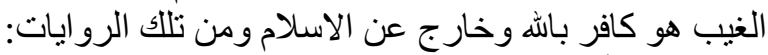

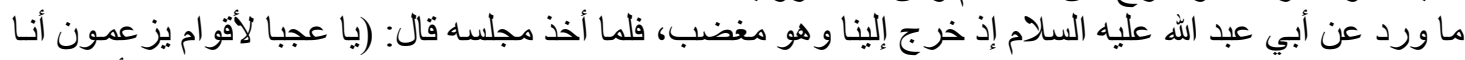

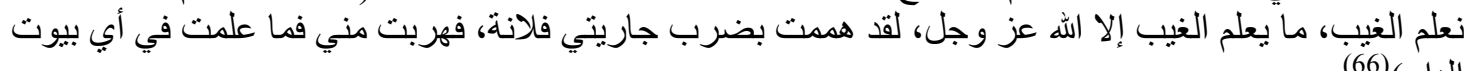

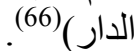
كذلك ذكر الثيخ الصدوق: ومن بنحل للأئمة علم الغيب. فهذا كفر باله، وخروج عن الإسلام عندنا(67.). 
International Journal on Humanities and Social Sciences

website:www.ijohss.com

Email:editor@ijohss.com

العدد (29) يناير 2022

ISSN: $2415-4822$

Volume (29) January 2022

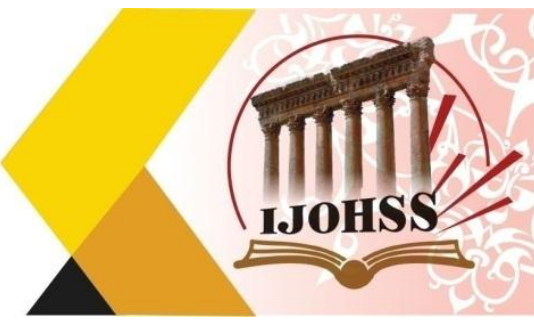

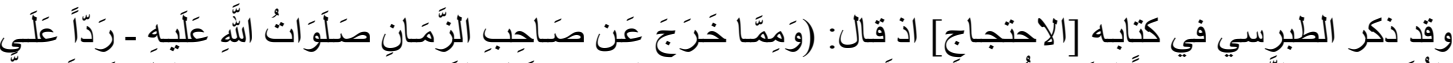

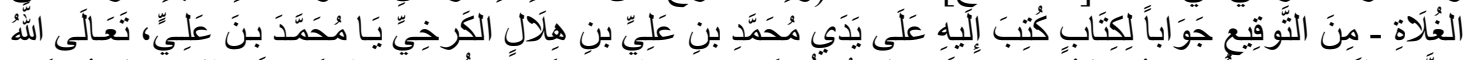

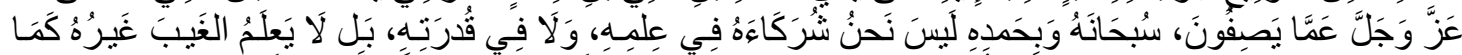

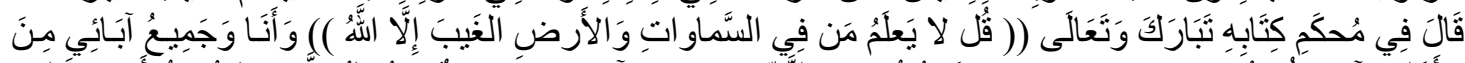

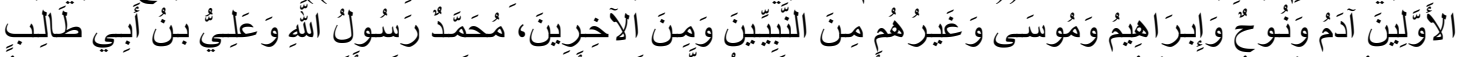

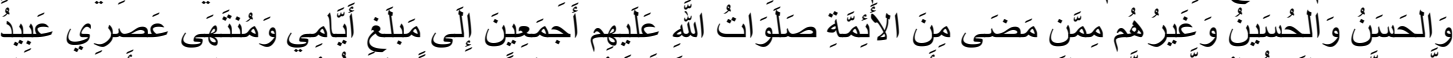

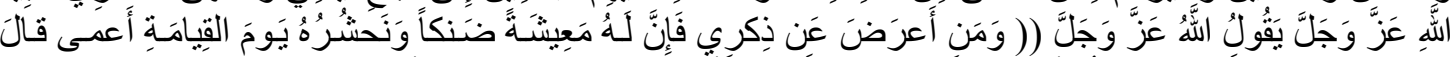

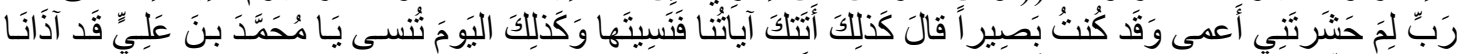

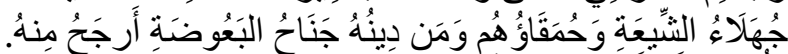

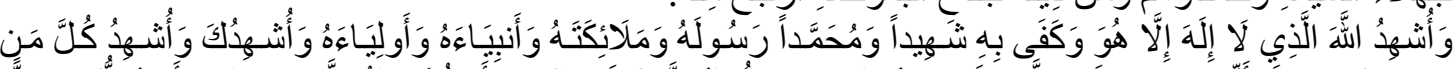

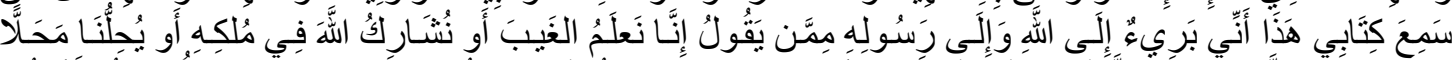

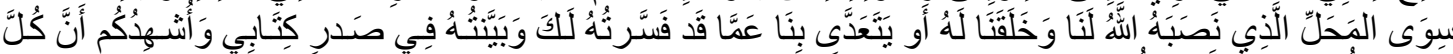

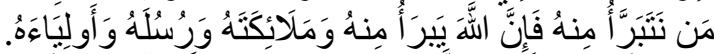

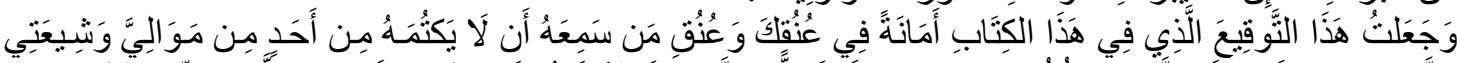

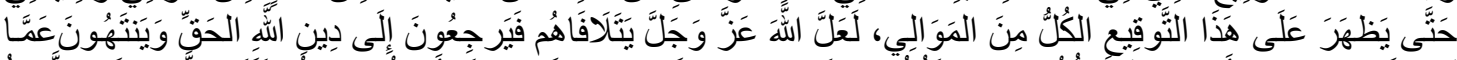

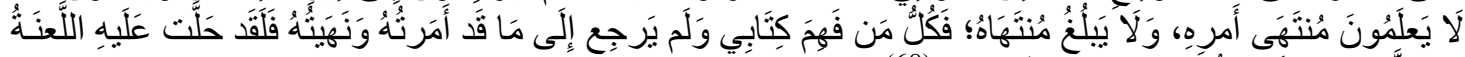

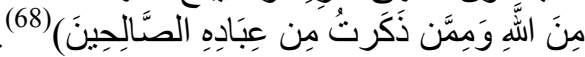

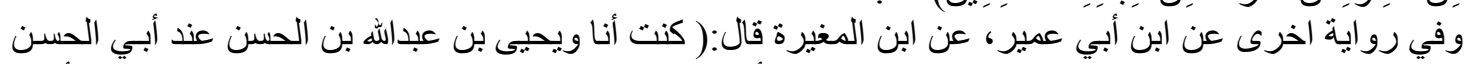

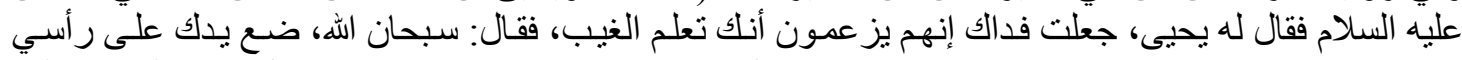

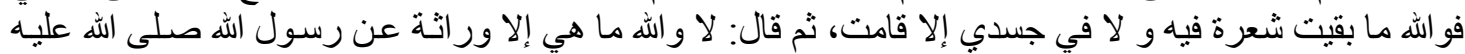

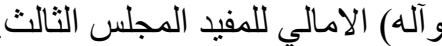

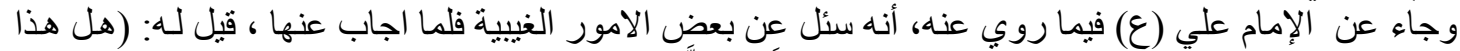

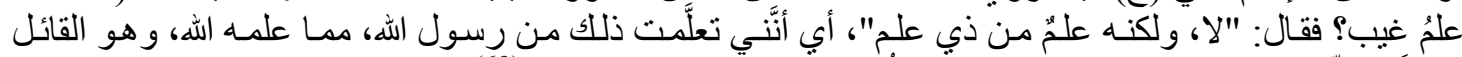

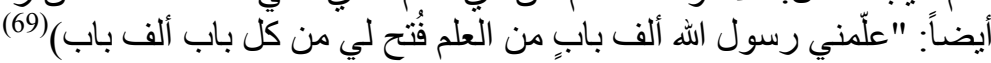

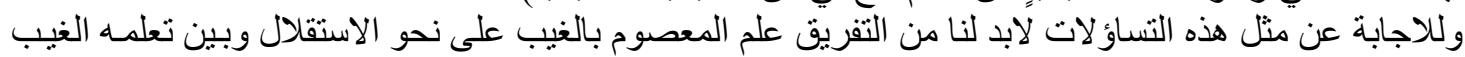

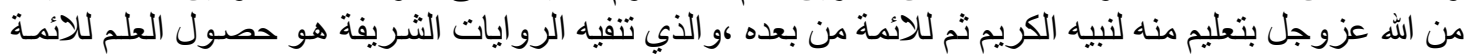

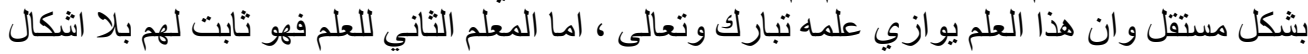

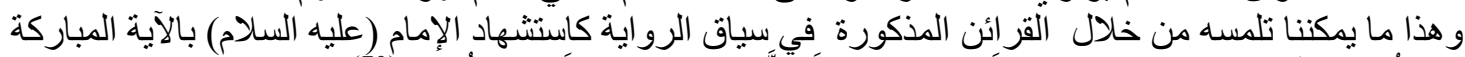

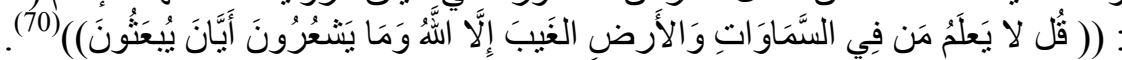

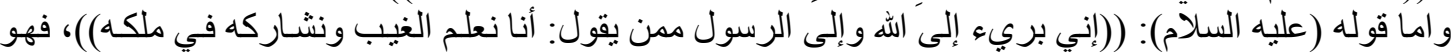

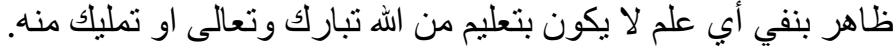

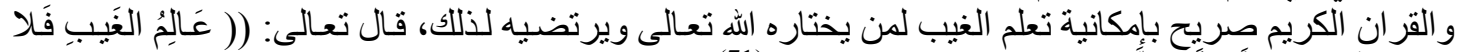

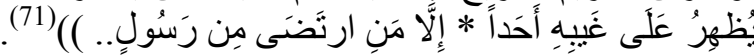

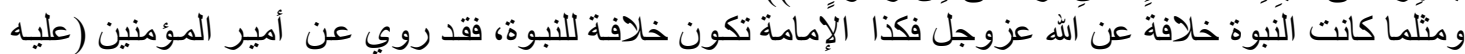

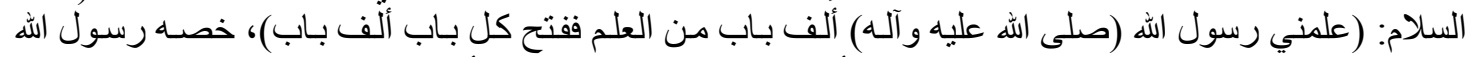

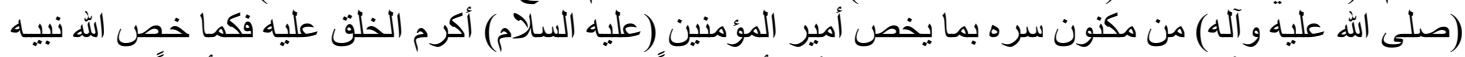

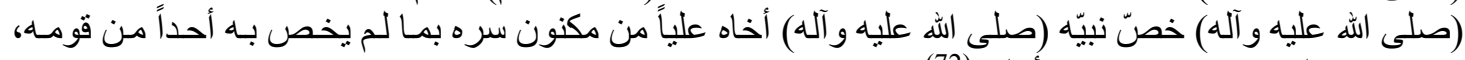

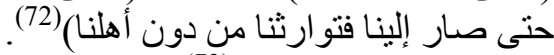

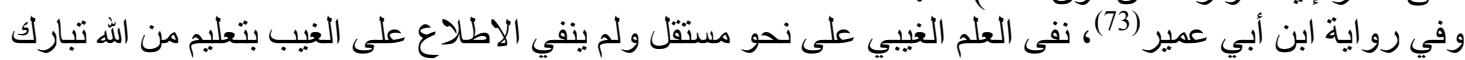

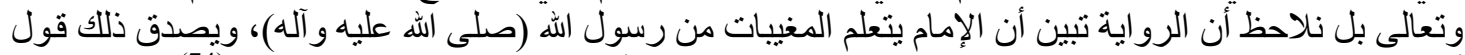

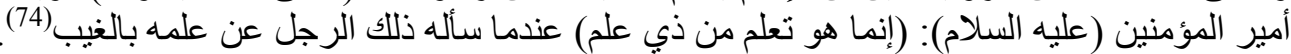


International Journal on Humanities and Social Sciences

website:www.ijohss.com

Email:editor@ijohss.com

العدد (29) يناير 2022

ISSN: $2415-4822$

Volume (29) January 2022

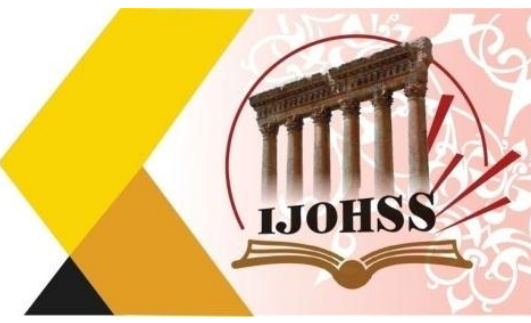

المطلب الثاني: اشكالات حول علم الائمة

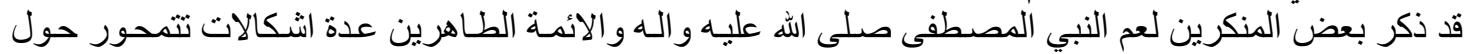

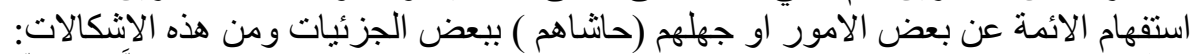

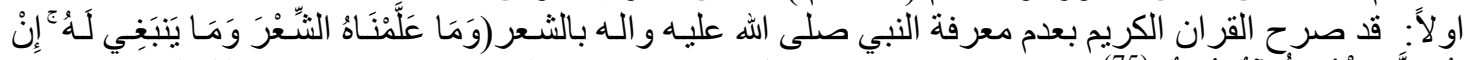

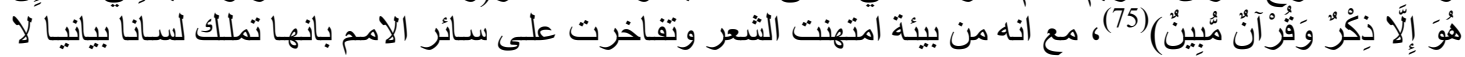

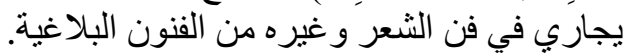

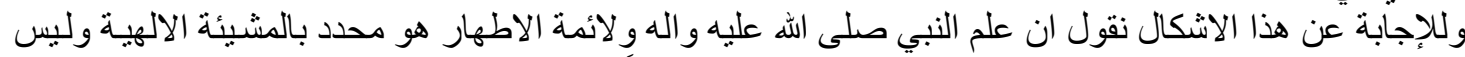

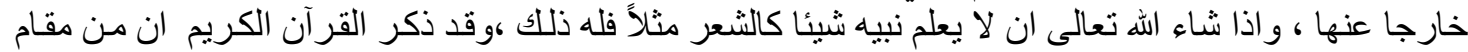

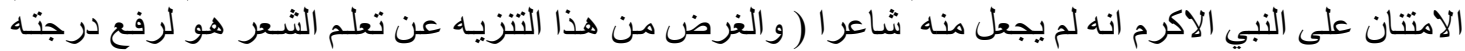

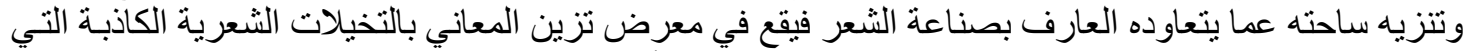

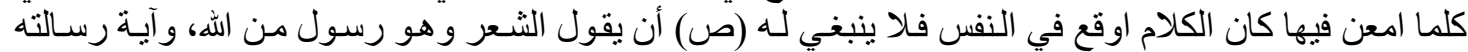

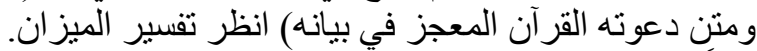

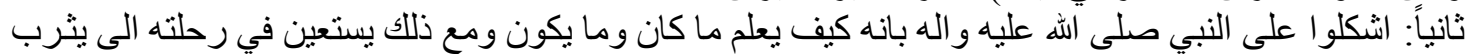

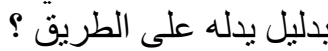

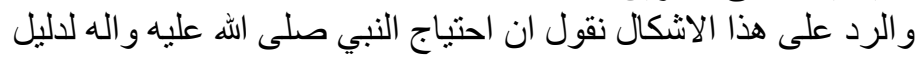

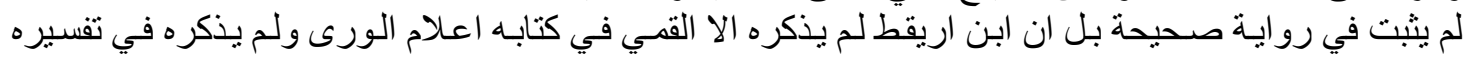

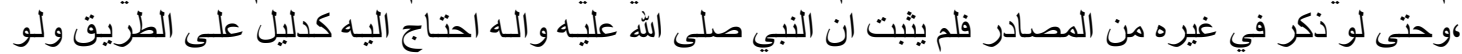

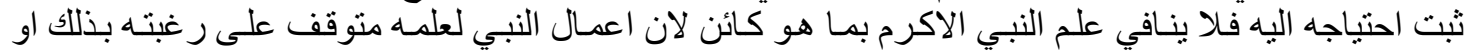

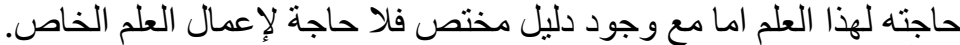

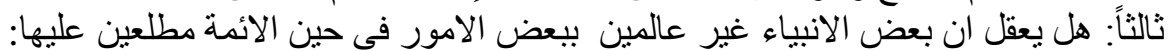

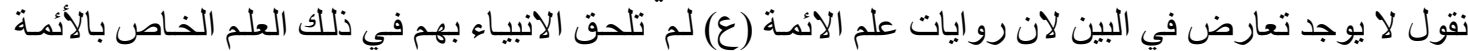

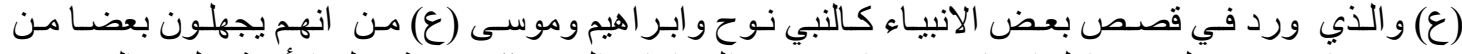

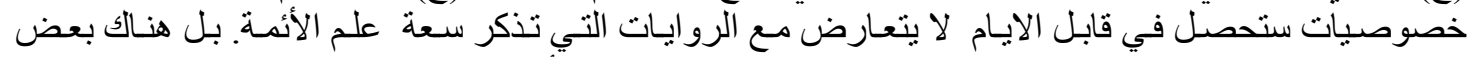

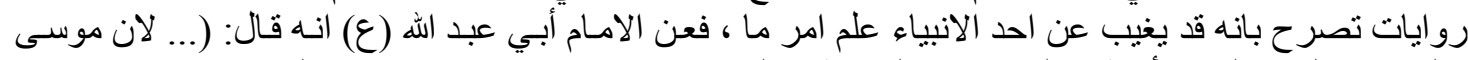

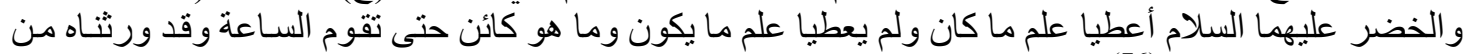

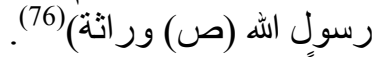

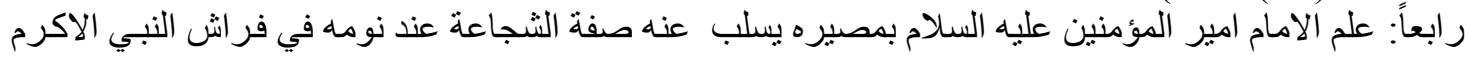

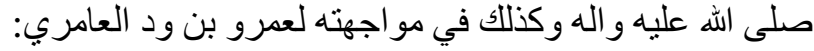

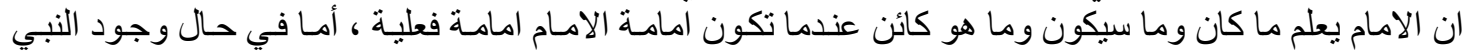

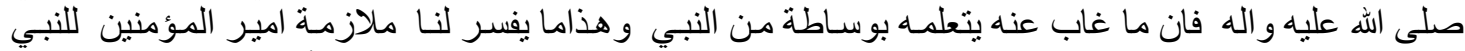

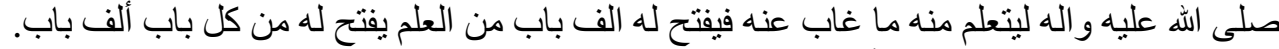

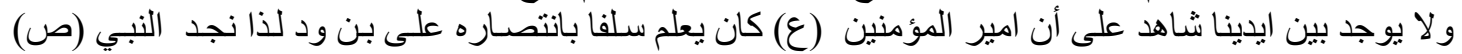

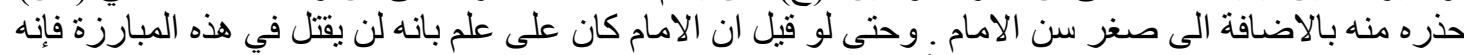

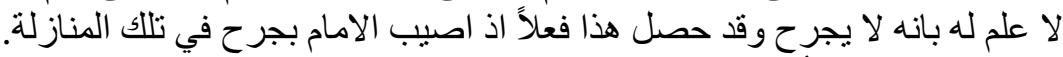

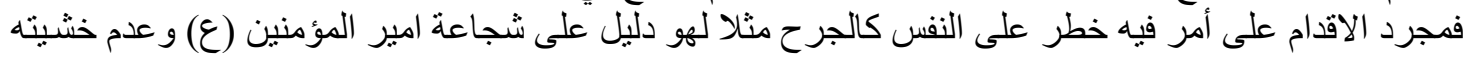

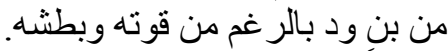

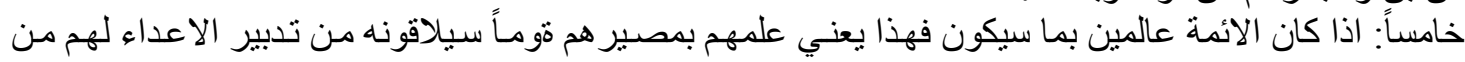

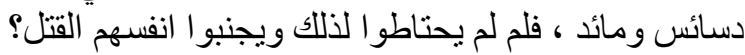

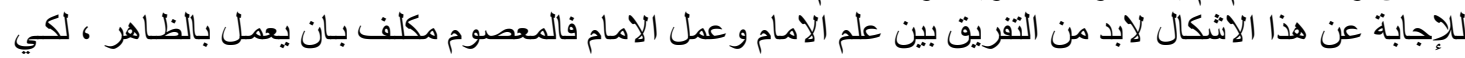

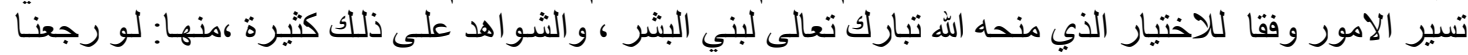

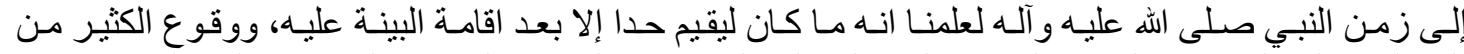

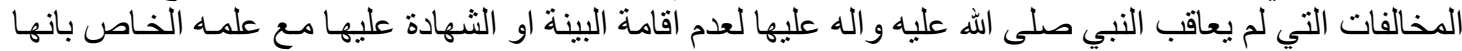
وقعت وما ذلك الا لعمله بظاهر الامور وبحسب مالف مأمور باله. 


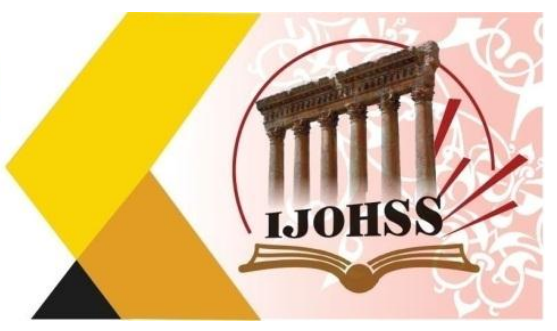

ومن الوقائع التي يمكن عدها شو اهدا على ذللك :

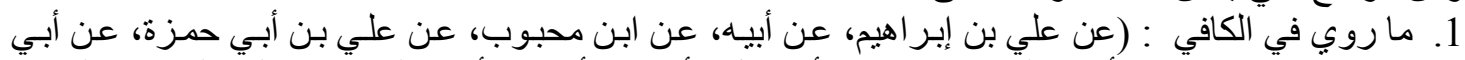

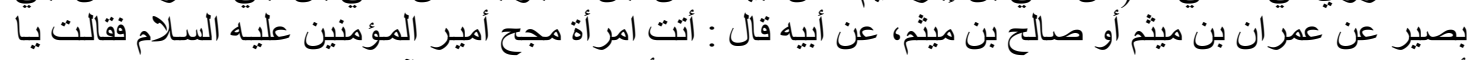

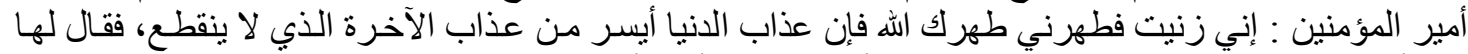

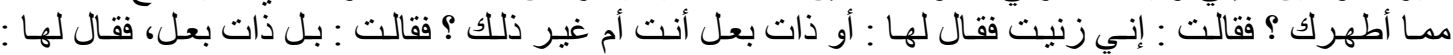

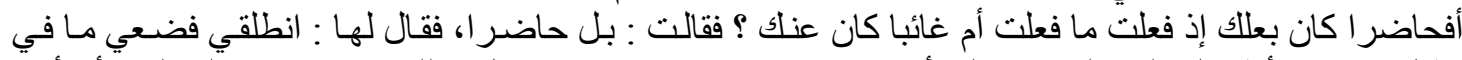

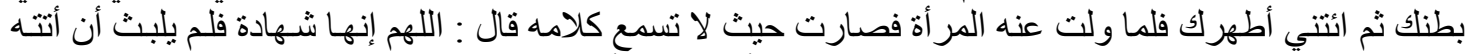

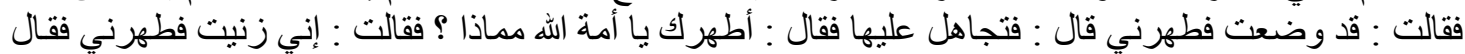

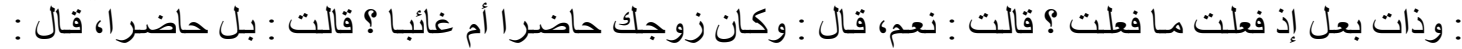

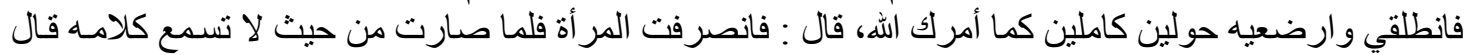

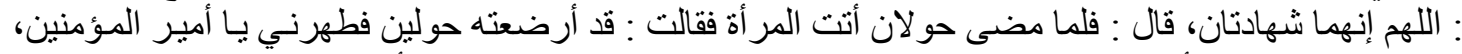

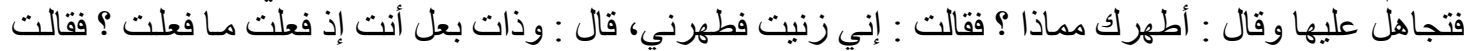

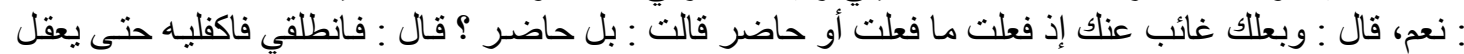

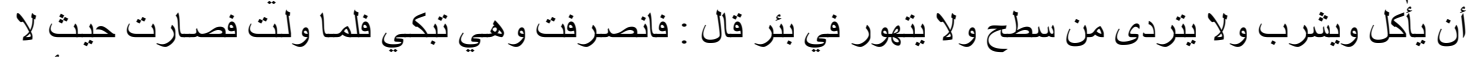

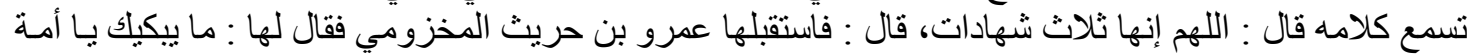

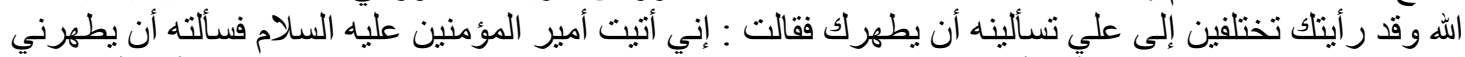

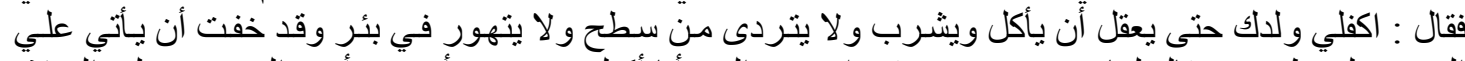

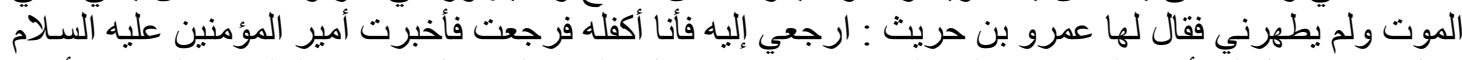

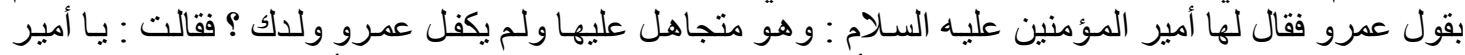

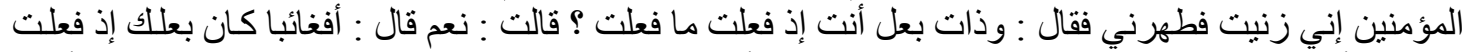

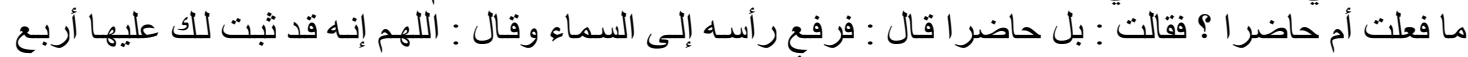

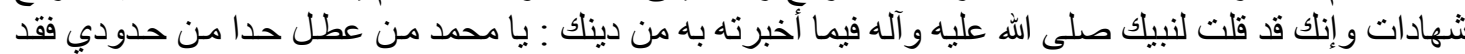

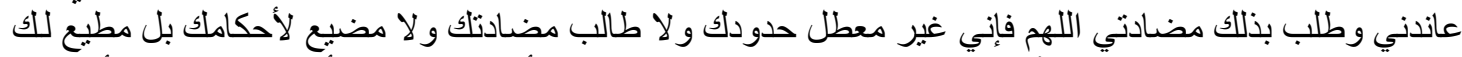

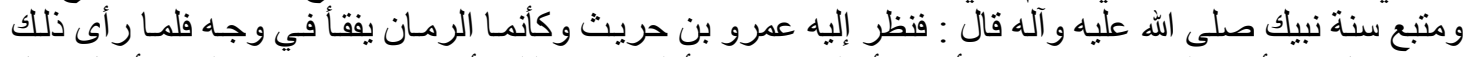

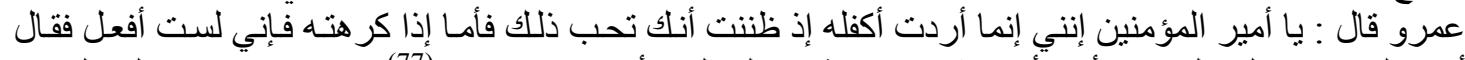

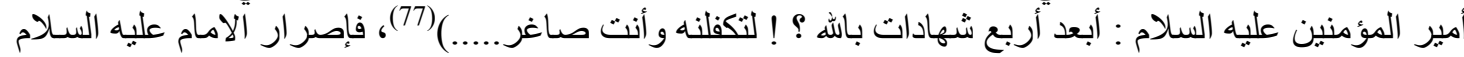

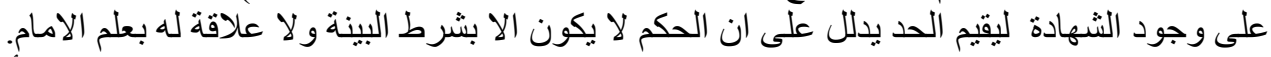

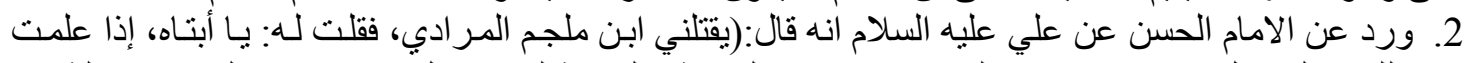

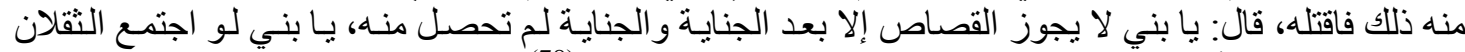

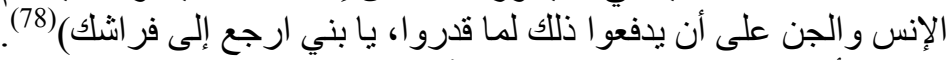

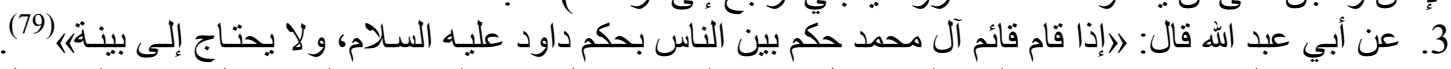

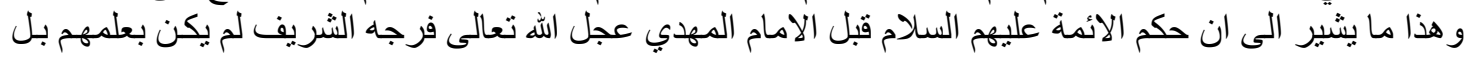

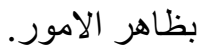

سادساً: اذا كان الائمة عليهم السلام مكلفين بان يعملو ا بظاهر الامور وان لا يقيمو ا حدا الا بعد وقوع الجريمة فلا

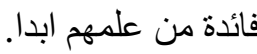

ويمكن الاجابة عن هذا الاشكال نقول:

هـ هناك اختلاف بين العلماء حول مسالة علم الامام ، هل هو تفصيلي حتى بالحو ادث الجزئية ام هو اجمالي لا على نحو التفصيل.

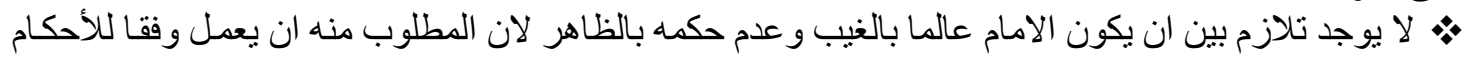

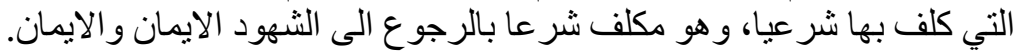

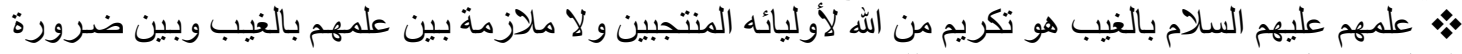
العمل به ، بل تبين سابقا ان الامر خلاف ذللك. 


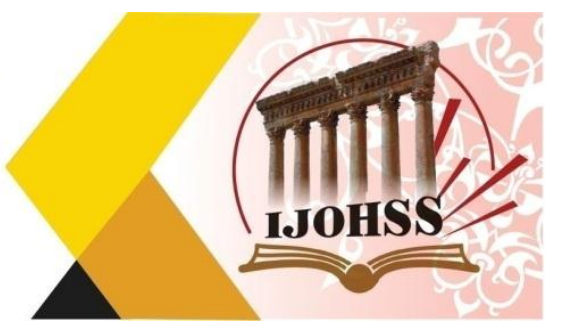

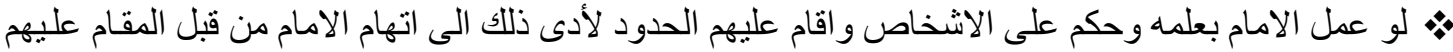

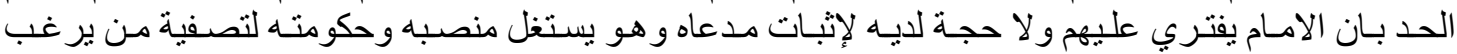
بتصفيته.

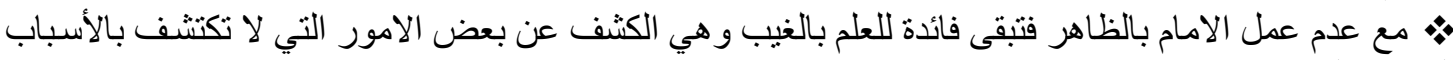

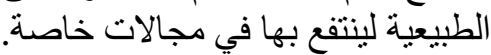

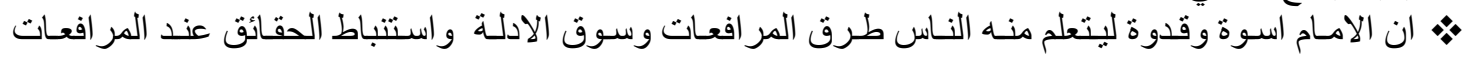
و القضاء، فلابد من ان يحكم بالظاهر تدريبا لعامة الناس فهم لا يتمكنون من معرفة الغيب.

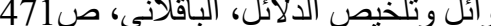

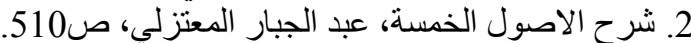

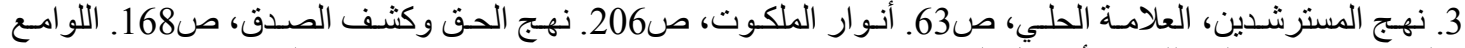

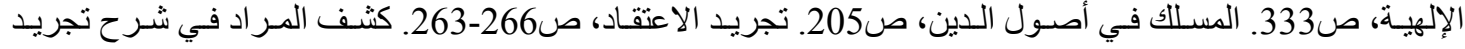

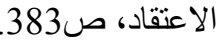
4. الذخيرة في علم الكلام، صلام، ص233. شرح جمل العلم و العمل، ص1949، 195.

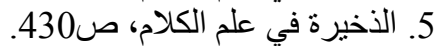

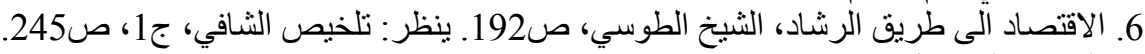

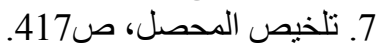

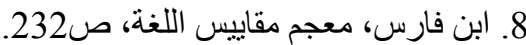

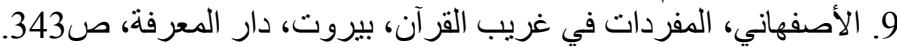

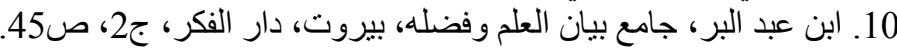

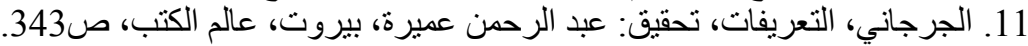

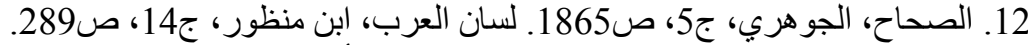

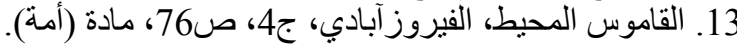

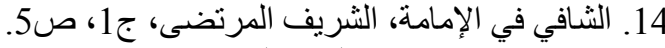

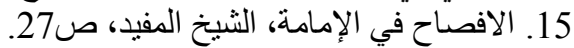

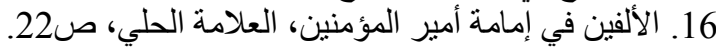

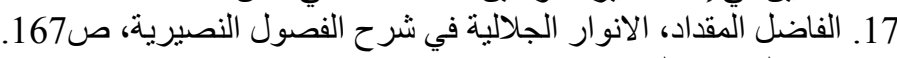

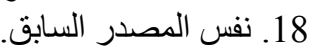

19. الاقتصاد الى طريق الرشاد، الطوسي، ص193.

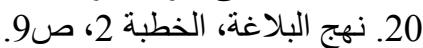

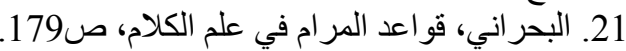

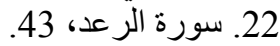

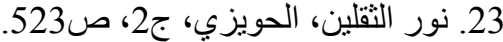

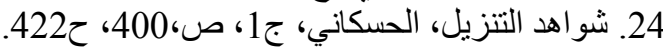

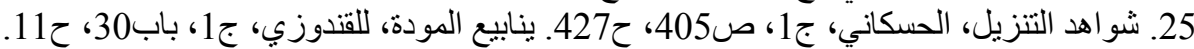

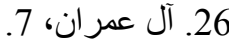

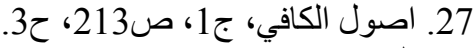

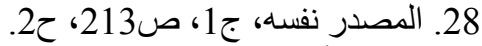

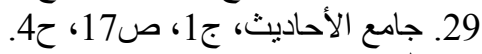

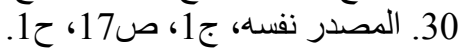

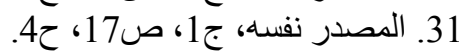

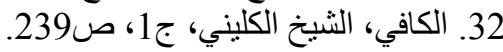
33. الكافي 241/1 النيخ ، بصائر الدرجات صفحة 174.

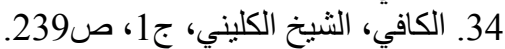

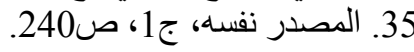


العدد (29) يناير 2022

Volume (29) January 2022

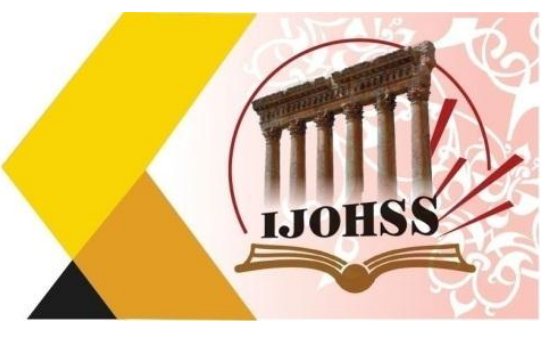

36. 3 المصدر نفسه، ج1، ص241.

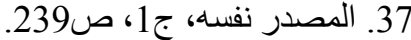

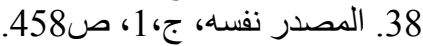
39. بحار الأنوار، العلامة المجلسي، ج26، ج26، ص46،

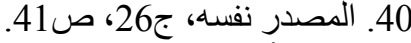

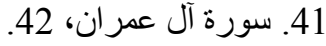

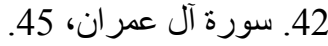

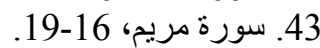

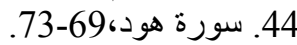
45. الكافي، الثيخ الكليني، ج1، صن، ص271.

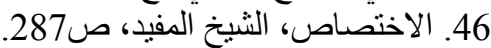
47. 4. سورة النمل، 40. 40.

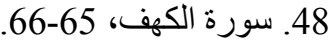
49. سورة الكهف، 48 الكي، 84-84. 50. الكافي، الثيخ الكليني، ج18، ص270، ص270.

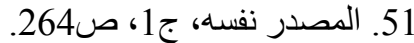

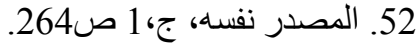

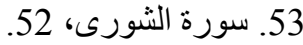
54. الكافي، الثيخ الكليني، ج1: الكي، ص273. 55. 5ورة الإسر اء، النيخ الكاني،

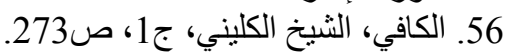

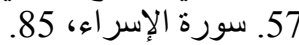

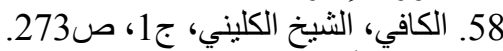

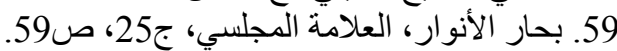

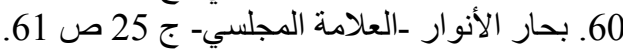

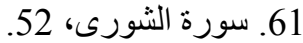

62. بحار الأنوار، العلامة المجلسي، ج26، ص26، ص58.

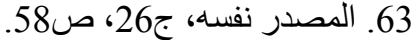

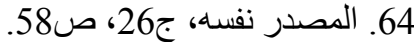
65. الكافي، الثنيخ الكليني، ج1، ص58202، صني، عيون أخبار الرضـا (ع)، الثيخ الصدوق، ج2، ص199، كتاب الغيبة، محمد

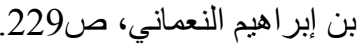

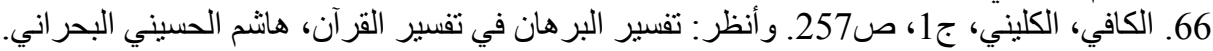

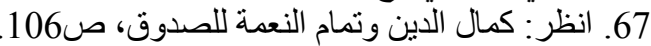

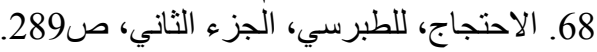

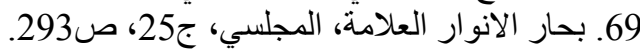

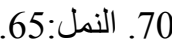

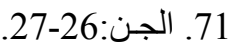

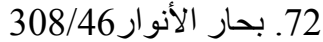

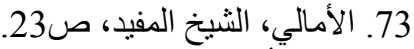

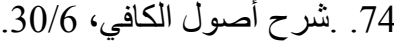

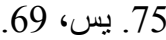

76. 75. الكافي، الثيخ الكليني، ج)، الصفحة ا7؟r.

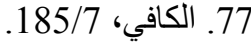

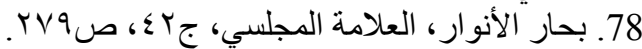

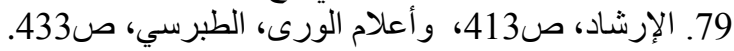




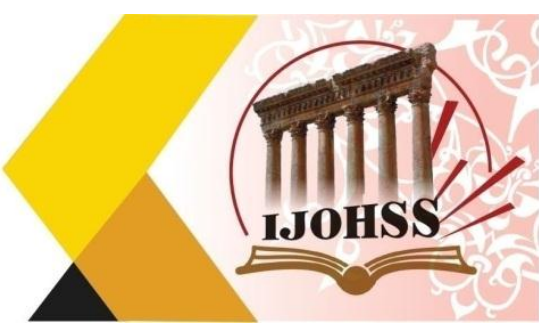

المصادر والمراجع - المران

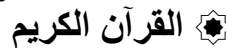

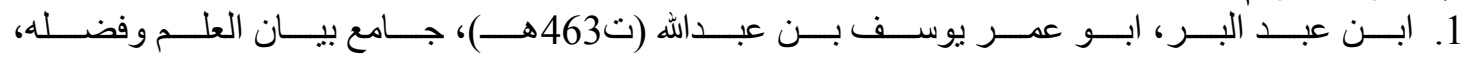

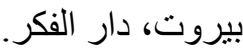

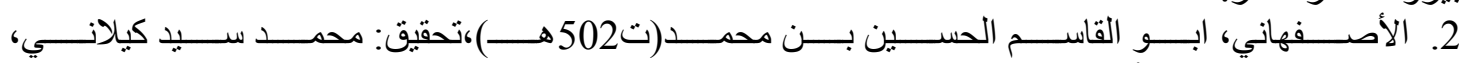

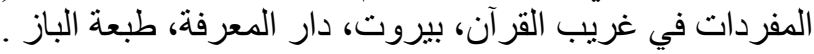

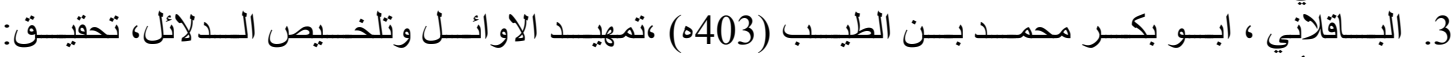

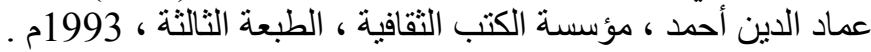

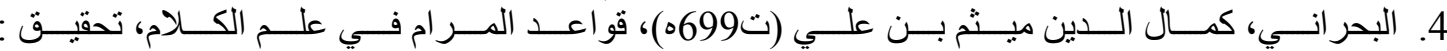

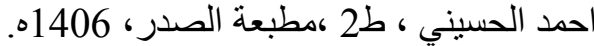

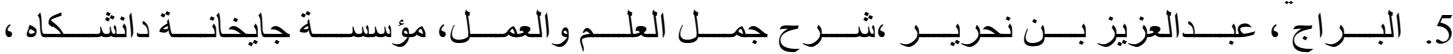

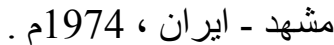

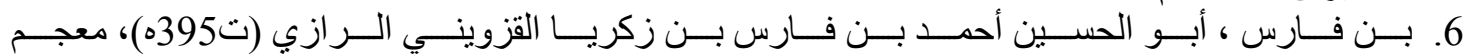

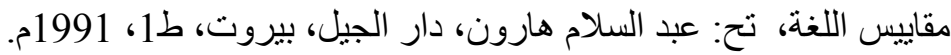

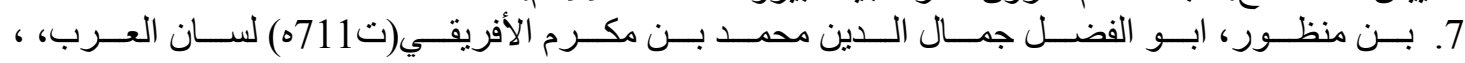

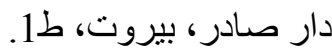

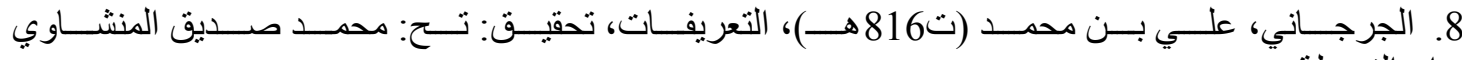

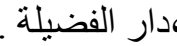

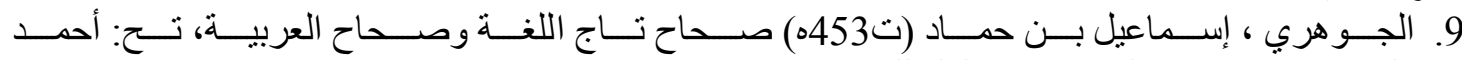
عبد الغفور عطار، ط4، القاهرة، دار العلم للملايين، 1977م.

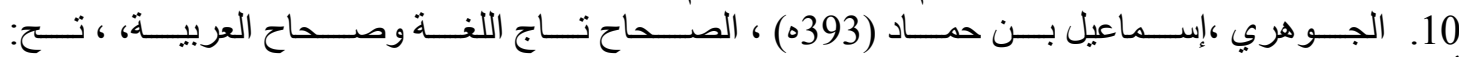

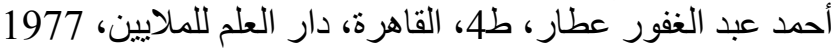

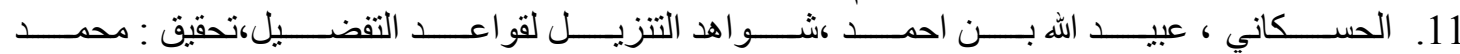

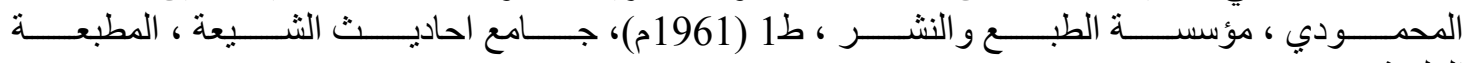

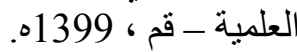

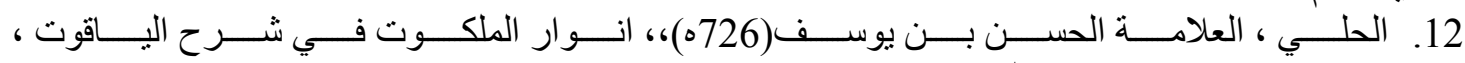

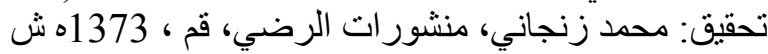

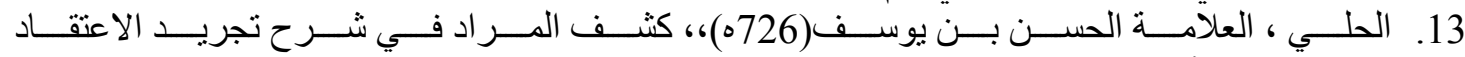

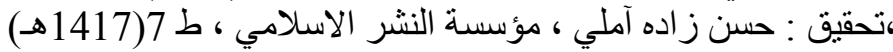

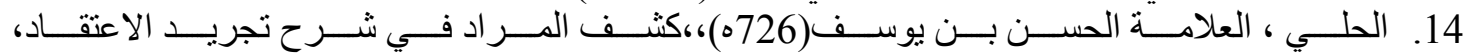

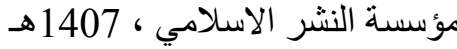

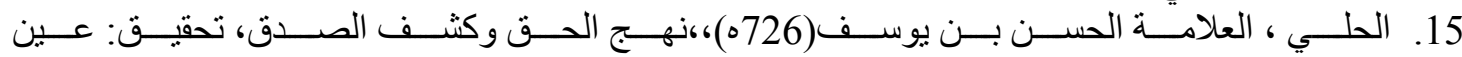

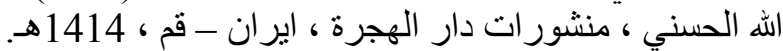

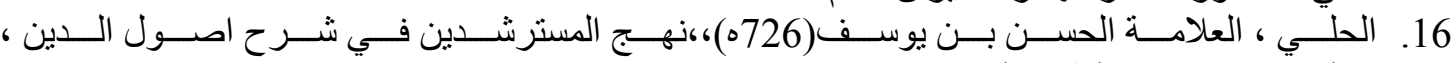

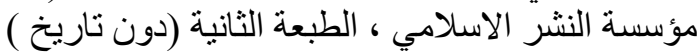

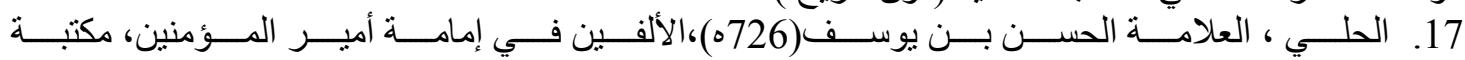

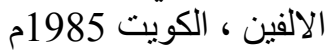

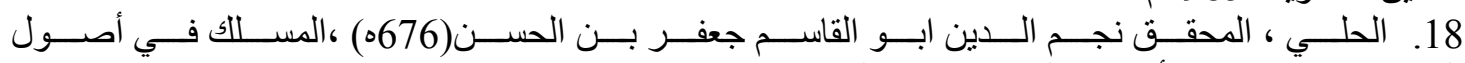

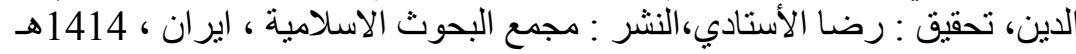

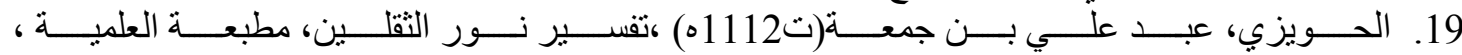

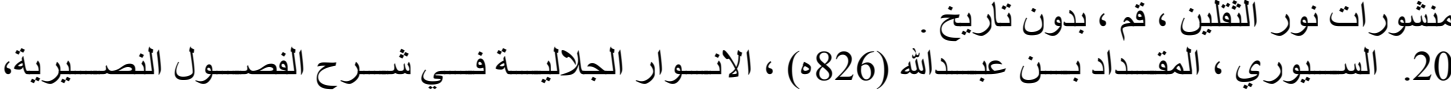

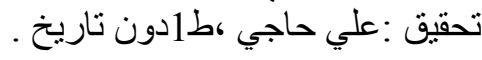




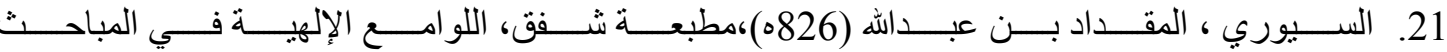

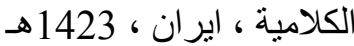

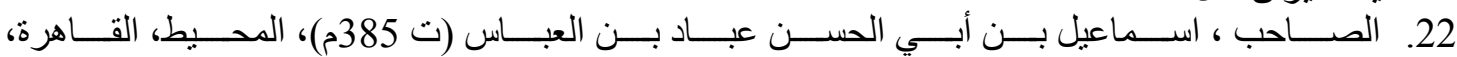
1962

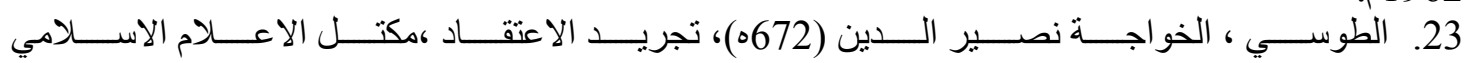
\$1407،

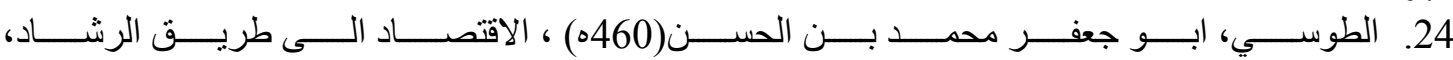
منشور ات مكتبة جامع جهلستون - طهران ، 1400 هـ البه

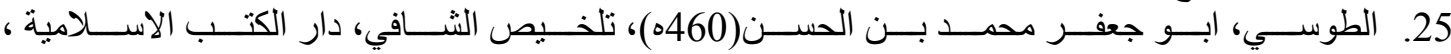

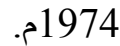

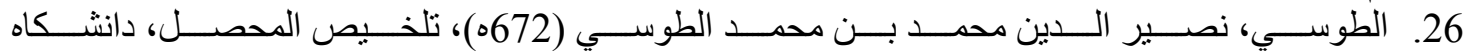

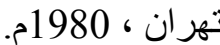

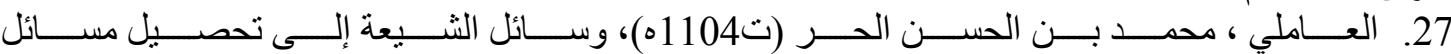

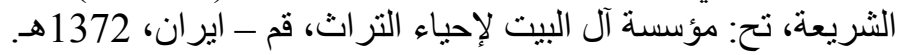

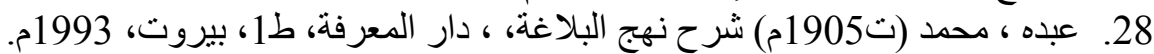

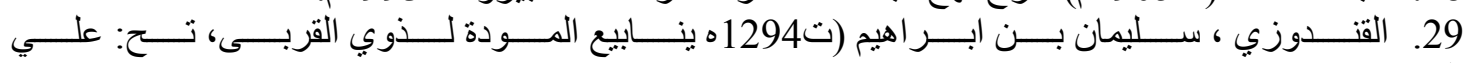

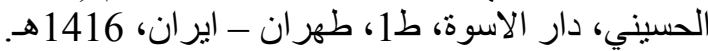

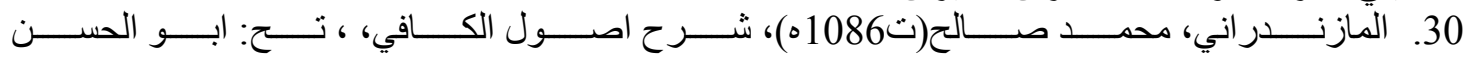

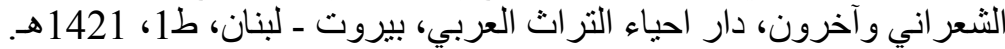

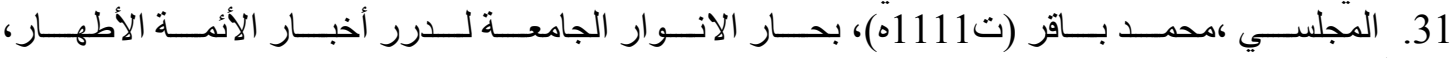
دار الكتب الإسلامي، طهران، 1413هـ.

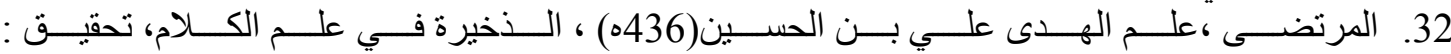

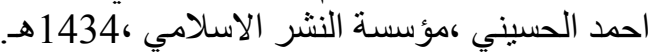

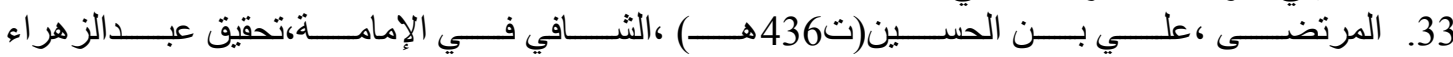

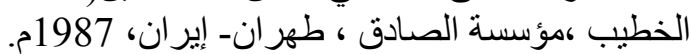

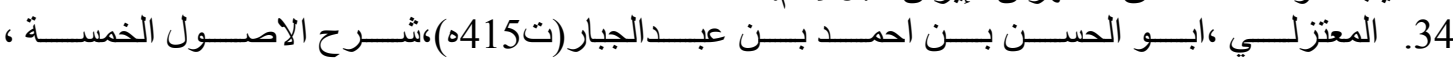

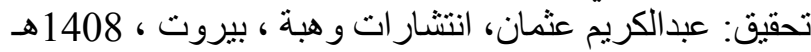

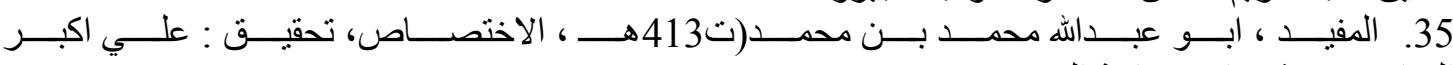
الغفاري ، منشور ات جماعة المدرسين -قم كد.ت.

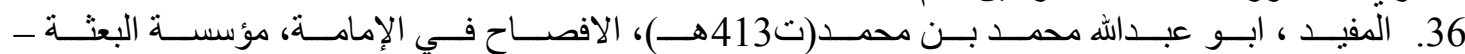
قم ،طان(1412). 